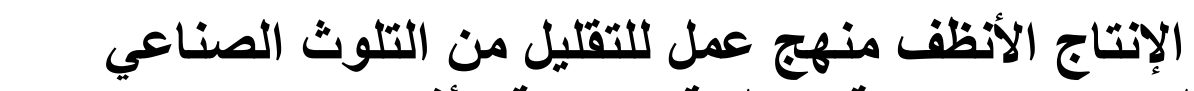

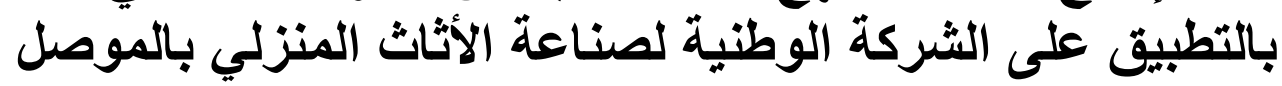

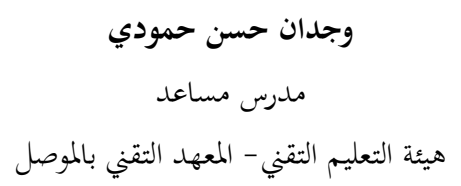

\author{
الدكتور عادل ذاكر النعمة \\ أستاذ مساعد -قسم الادارة الصناعية \\ كلية الإدارة والاقتصاد - جامعة الموصل
}

wijdanhassan@yahoo.com

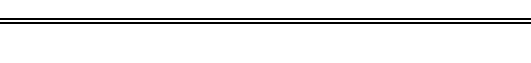

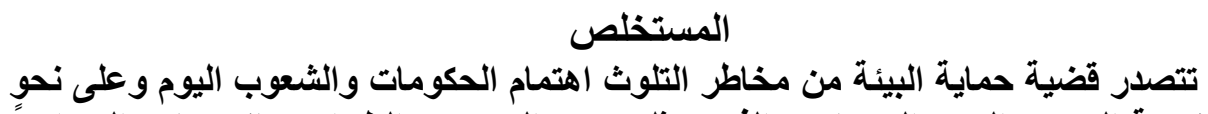

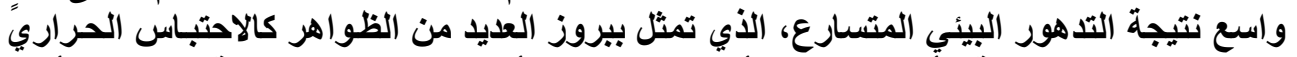

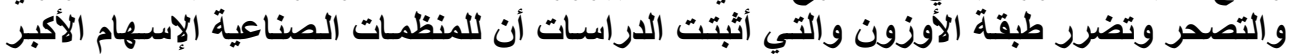

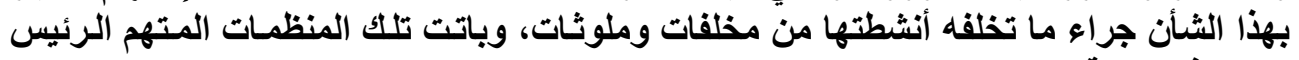
إزاء هذه الحالة.

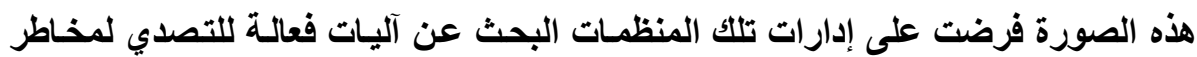

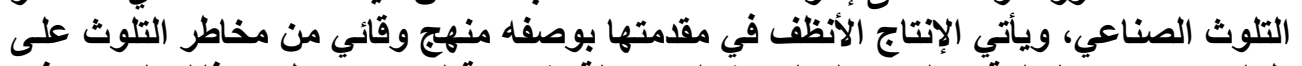

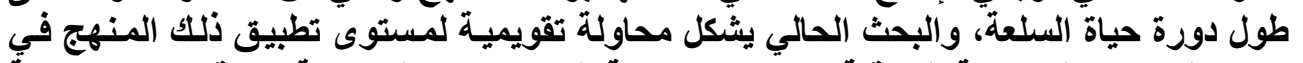

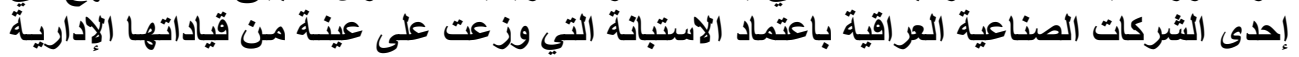

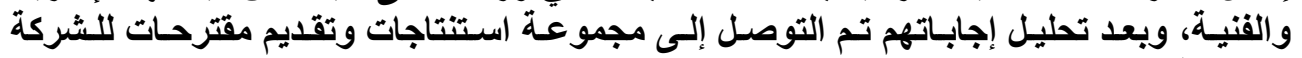

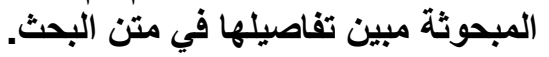

الكلمات المفتاحية: الإنتاج الأنظف، التلوث الصناعي.

\section{Cleaner Production a Work Approach to Decrease Industrial Pollution: Application on National Company for Furniture Industry in Mosul}

Adel Th. Al-Nema (PhD)

Assistant Professor

Department of Industrial Management

University of Mosul
Wijdan H. Hammody

Assistant Lecturer

Foundation of Technical Education

Mosul Technical Institution

wijdanhassan@yahoo.com

\section{Abstract}

The problem of environment protection has been attracted by the governments and peoples' interest. This is due to the increasing environmental deterioration, because the raise of some phenomena such as global warming, green-house effect, desertification and

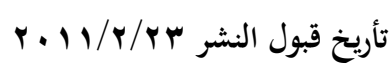

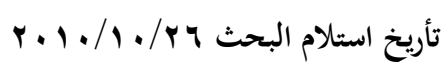


the damage of ozone. The modern studies have recently proved that the industrial organizations have magnificent contribution in this matter, as a result of remnants pollutions have been left, and consequently the organizations became the most accused aspect against this issue. This situation motivated these organizations to find effective mechanisms to resist the industrial pollutions. The cleaner production technique is on the head of these mechanisms as preventive approach agents the risks of pollution throughout the production life cycle. The present study is an evaluative initiation to the level of application in one of the industrial company in Iraq. The study contains questionnaire given to a sample of technical and administrative leader. After the analysis of their replay, some conclusions were drawn and also some suggestions were presented to the company, with the full details in the research.

Keywords: cleaner production, industrial pollution.

المقدمة

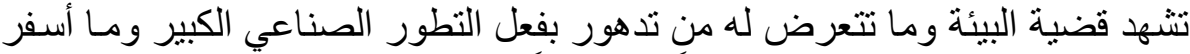

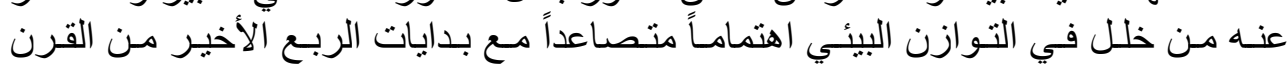

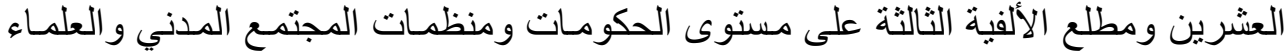

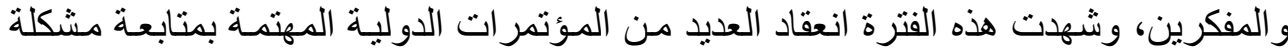

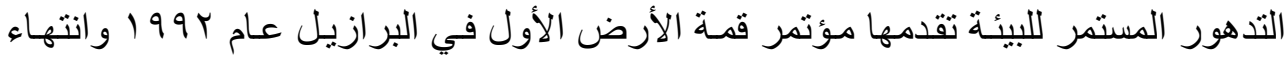

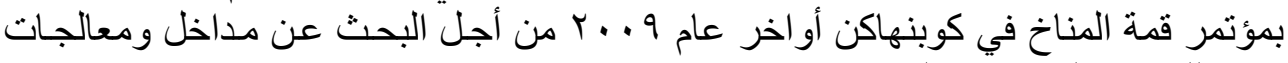
جدية للتصدي لمشكلات البيئة.

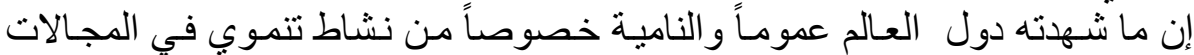

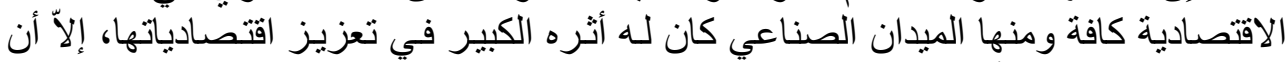

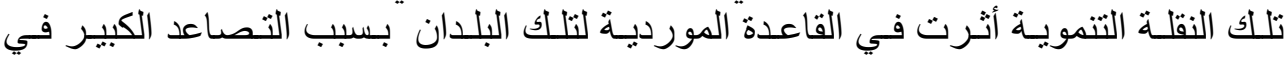

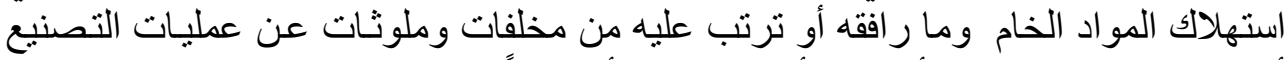
أخذت طريقها إلى الهو اء أو الماء أو التربة مما أثر سلباً في الحيـاة البشرية والنظم الحياتية عموماً.

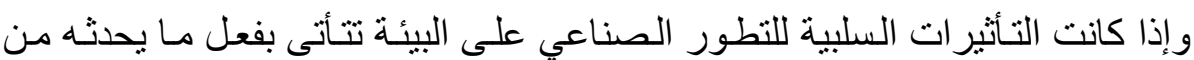

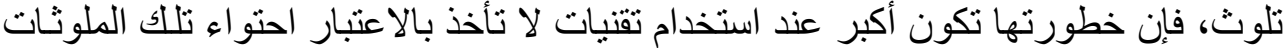

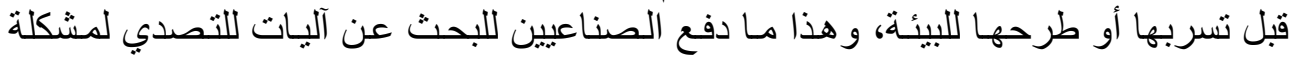

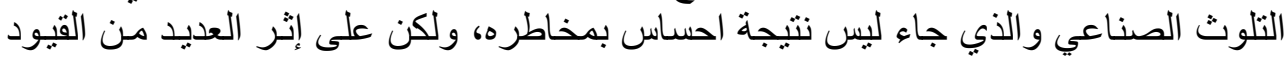

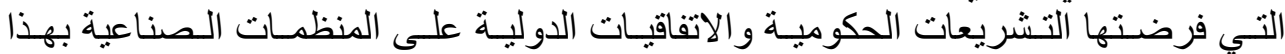

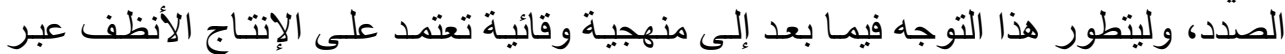

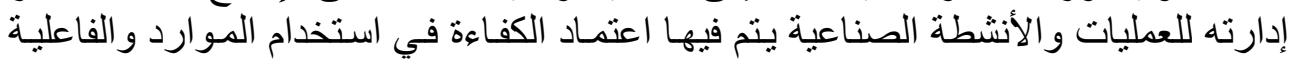

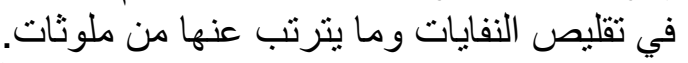

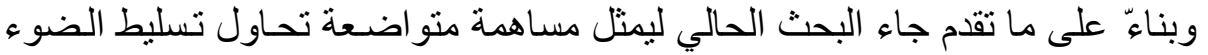

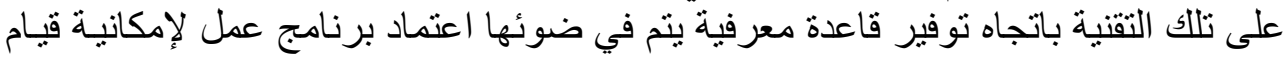

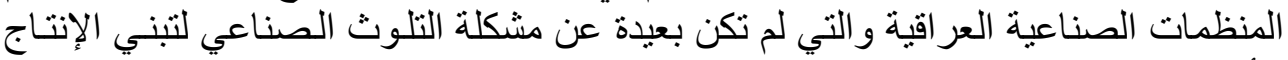

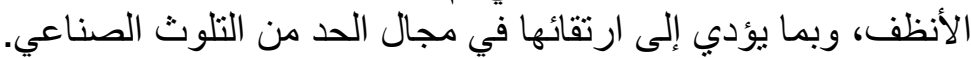

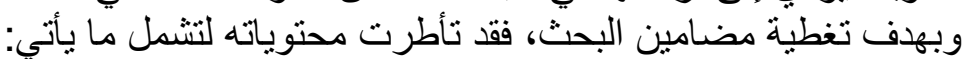


النعمة وحمودي[TV]

أولاً: الإطار المنهجي (منهجية البحث) ثانياً: الإطار النظري الإنهي ثُاثثاً: الإطار التطبيقي (الميداني) أولاً- الإطار المنهجي للبحث مشكلة البحث الاطث المن

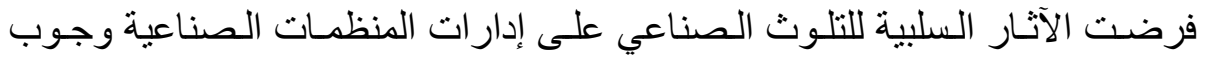

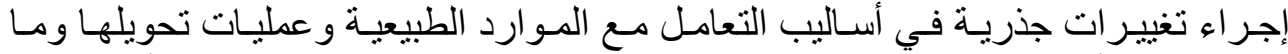

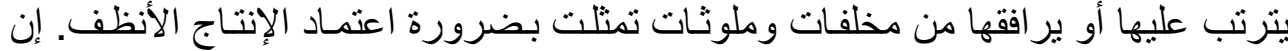

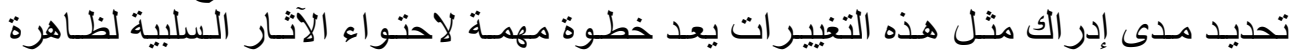

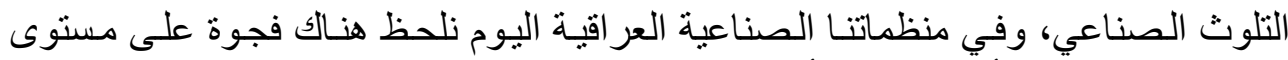

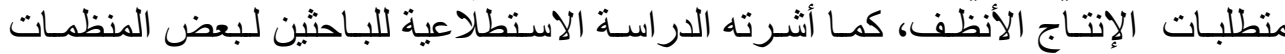

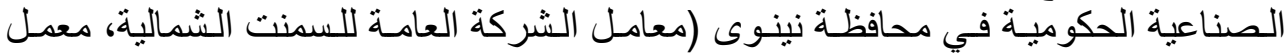

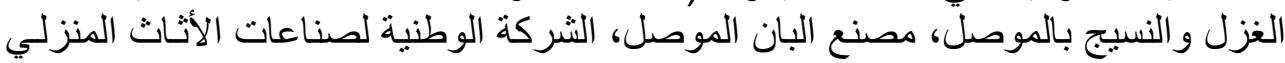

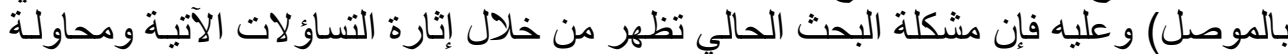

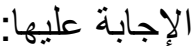
ــ هل الحـد من ظـاهرة التلوث الصناعي في الثركة المبحوثـة يتحقق من خـلال الإنتاج الأنظف

- هل منطلبات اعتماد الإنتاج الأنظف متاحة للشركة المبحوثة؟ الإنج ـ ما مستوى اعتماد الثركة المبحوثة للإنتاج الأنظف للحد من النلوثن الصناج الصناعي؟

أهمية البحث البث

يستمد البحث أهميته بوصفه محاولة لتسليط الضوء على الإنتاج الأنظف في مجال

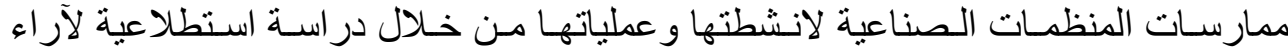

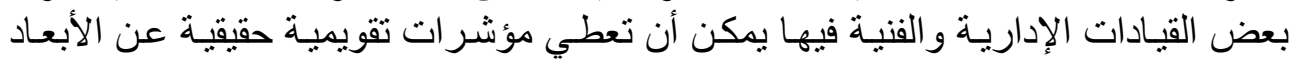

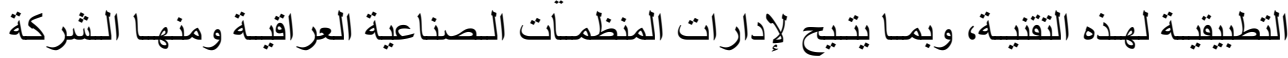

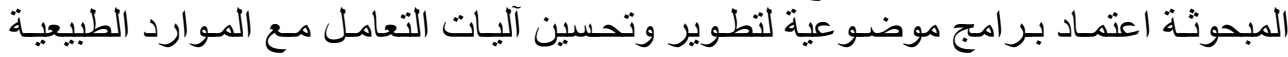

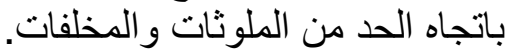

تعزيز اً لأهمية البحث، نعرض الأهداف البحثية الآتية:

أهداف البحث 1. تسليط الضوء على التوجهات العلمية المعاصرة ممثلة بالإنتاج الأنظف في مجال العال الحد من ظاهرة التلوث الصناعي. r. تقييم مستوى تو افر منطلباتِ الإنتاج الأنظف في الشركة المبحوثنة وتحديد الأساليب و الوسائل التي يمكن أن تدعم إمكانبات تطييقها.

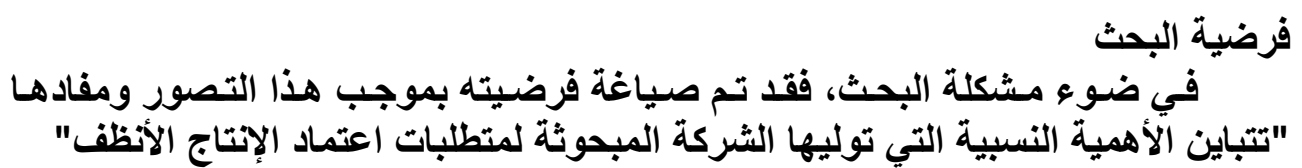


استتد البحث في إطلاره النظري على المنهج الوصفي في في عرض الأطر النظريـة

\section{منهج البحث}

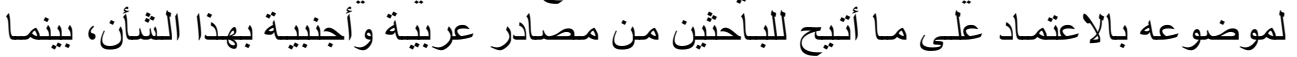

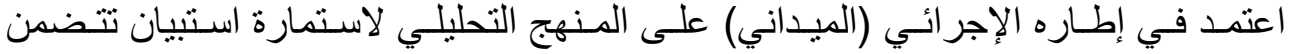

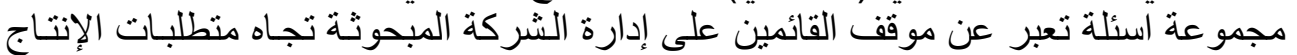
الأنظف ومديات اعتمادها.

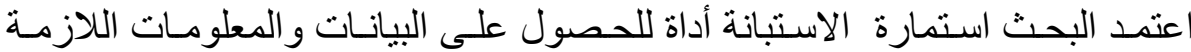

أداة البحث

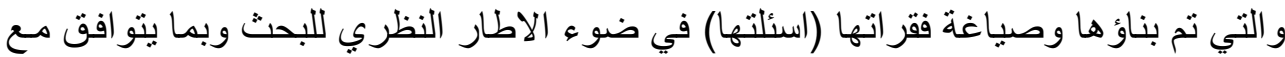
تساؤلات وفرضية البحث بهدف استطلاع آراء المبحوثيين حول المتطلبات التطبيقية للإنتاج

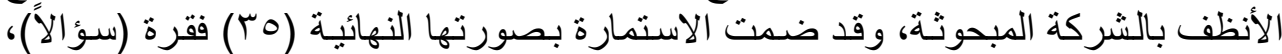

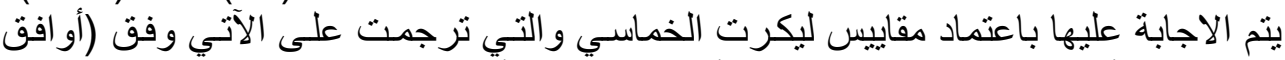

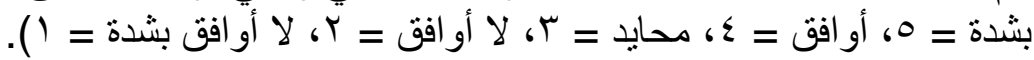

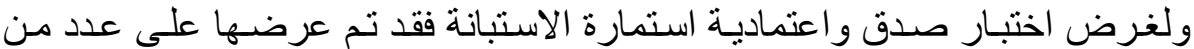
التدريسيين في كليـة الادارة و الاقتصـاد بجامعـة الموصل (هم كل من :أ.د.أكرم الطويله،

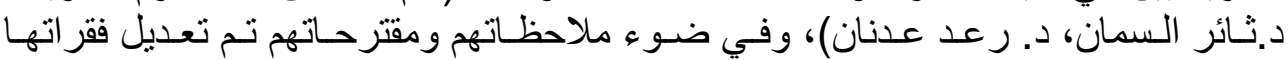

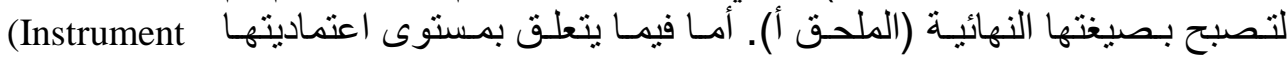

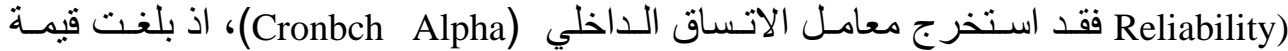
لجميع فقرات الاستبانة (Alpha)

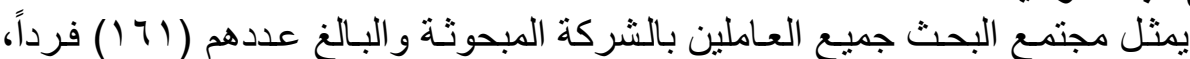

\section{مجتمع البحث وعينته}

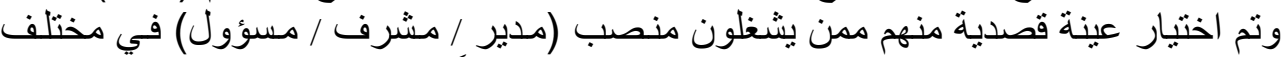

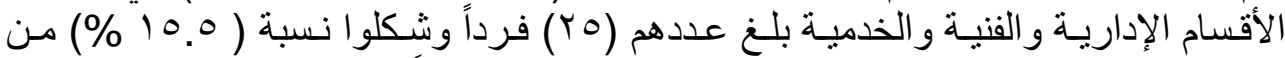

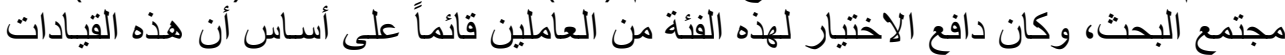

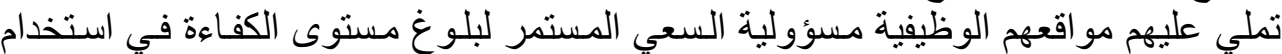

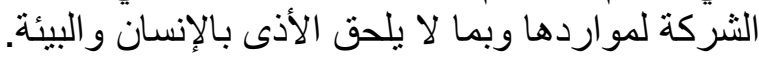

الحدود المكاتية للبحث التئ

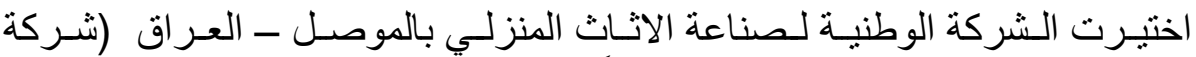

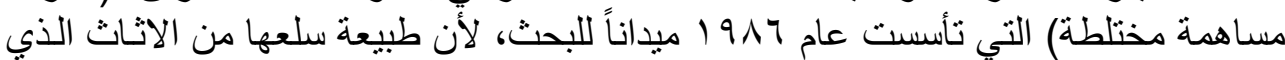

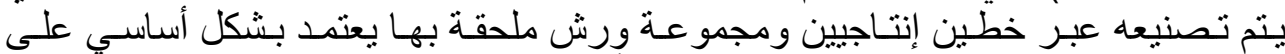

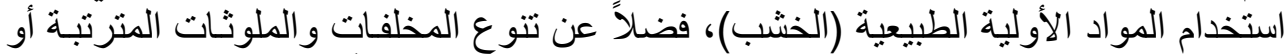

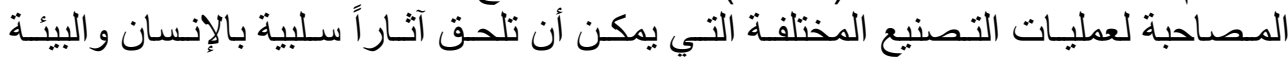
المحيطة. 
النعمة وحمودي[79]

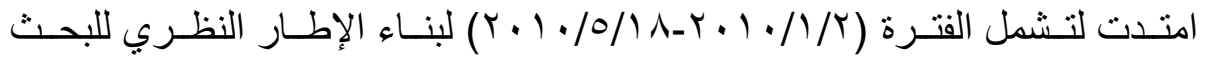

و إنجاز الدر اسة التطبيقية.

استخدم البحث البرمجية الإحصائية (SPSS) لتحليل بيانات الاستبانة باعتمـاد التحليل

أدوات التحليل الإحصائي

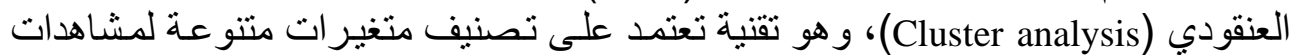

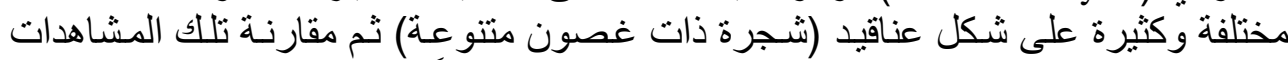

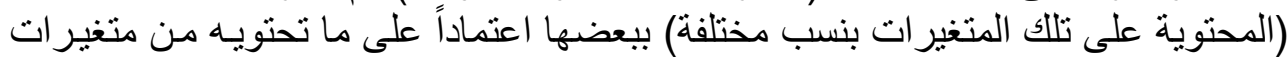

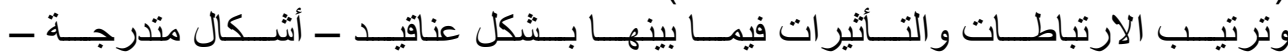

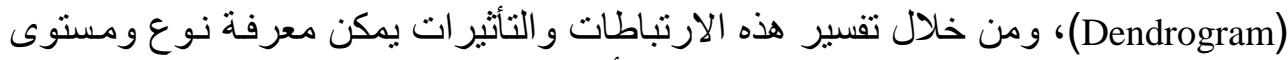

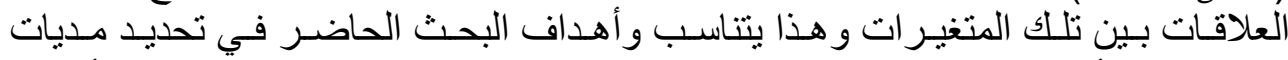

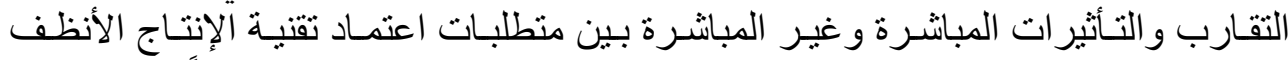

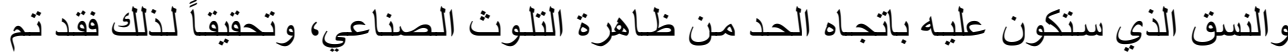

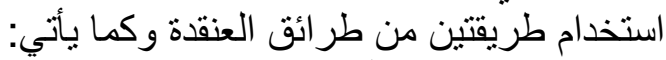

ا ـ العنقدة المتسلسلة (Hierarchical Clustering Analysis)

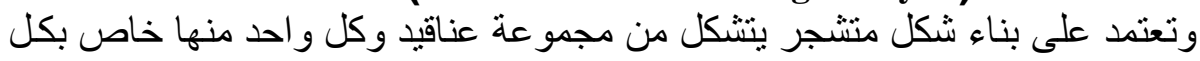

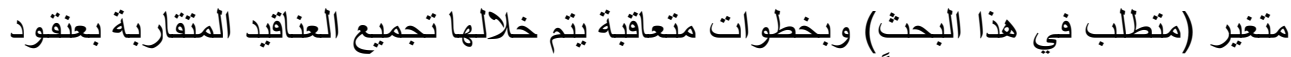

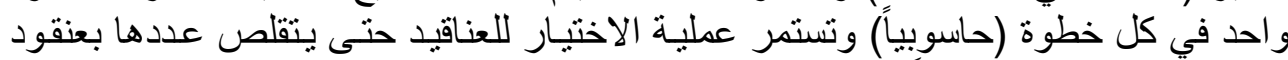

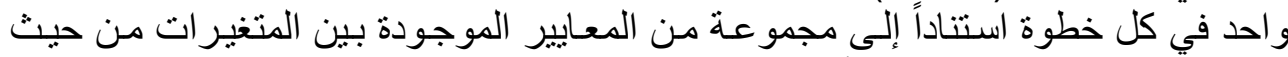

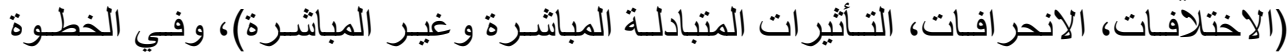

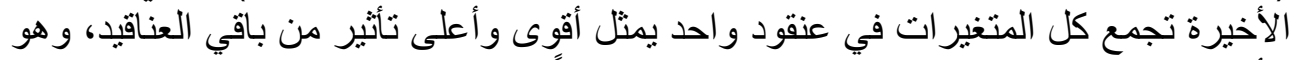
الأساس الذي تستتد عليه التحليلات و التفسيرات لاحقاً.

r العنقدة غير المتسلسلة (Non Hierarchical Clustering Analysis)

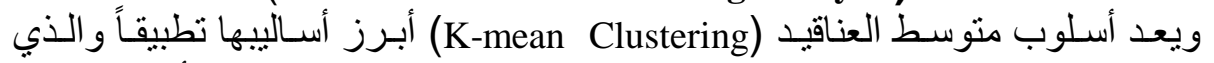

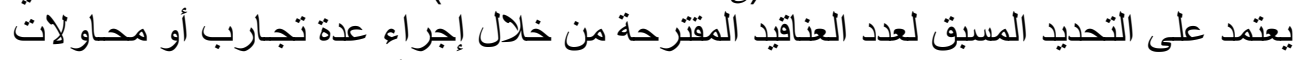

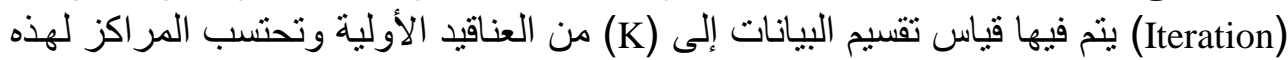

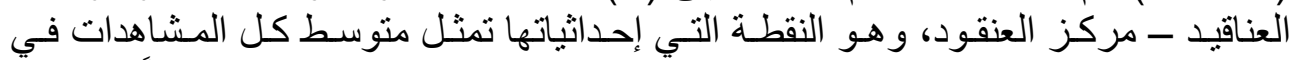

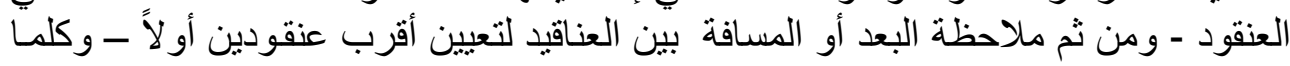

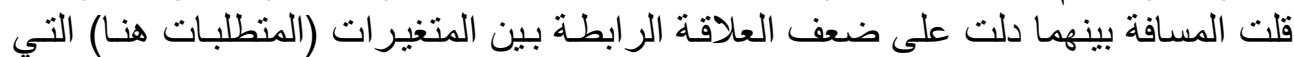

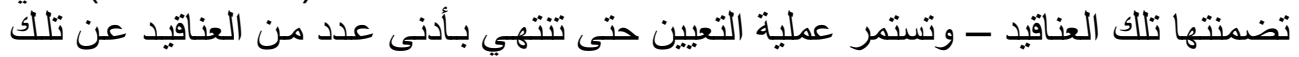
المشكلة في طريقة العنقدة المتسلسلة.

ثانياً- الإطار النظري

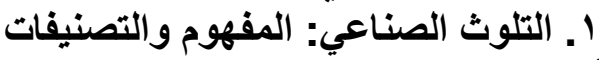
أ. مفهوم التلوث الصناعي الصين 


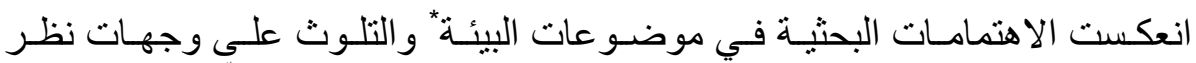

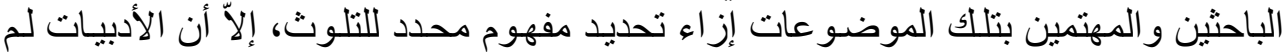

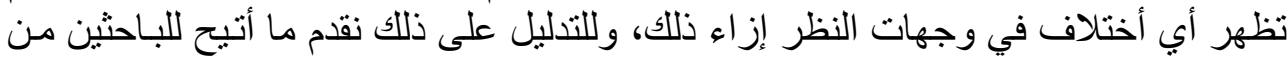

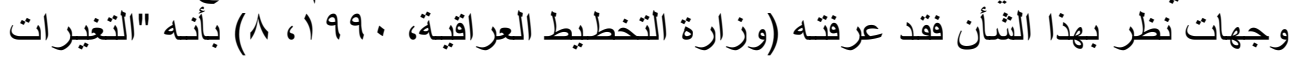

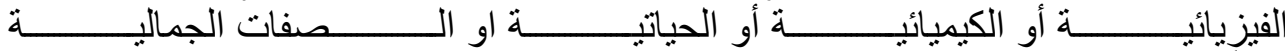
(كلاً أو بعضاً) التي تحدث في الماء و الهواء وتؤدي إلى تغيير نو عيتها ومو اصفاتها بحيث

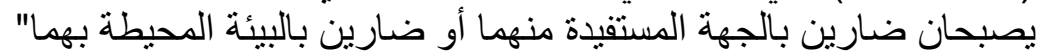

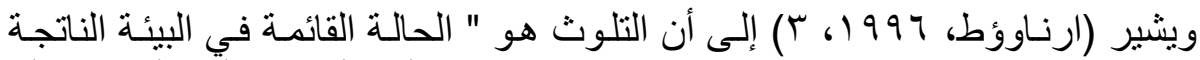

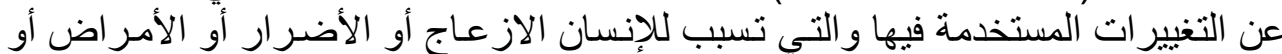

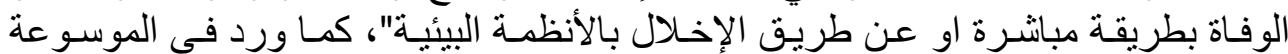

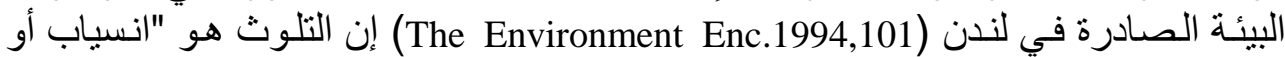

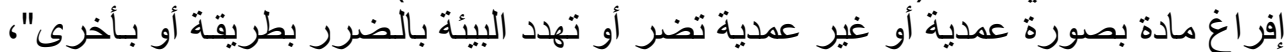

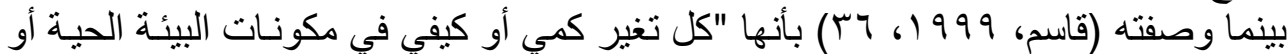

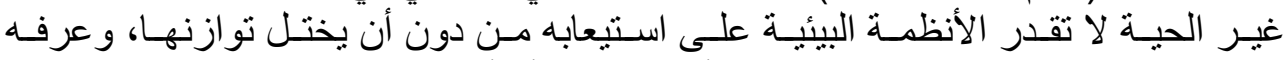

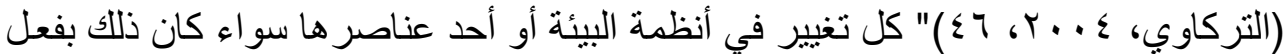

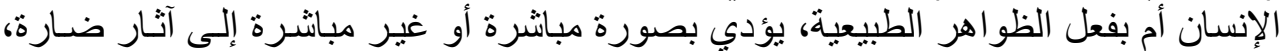

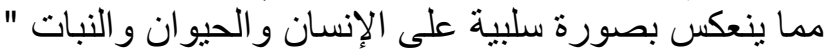

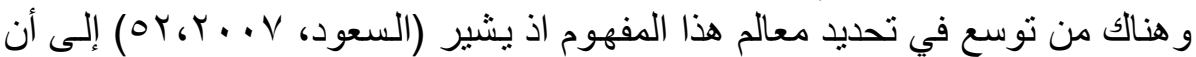

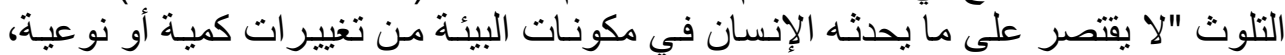

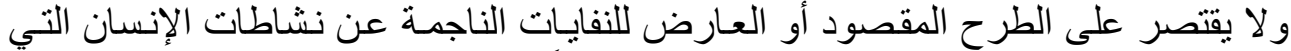

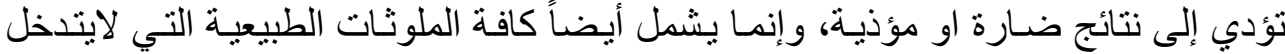

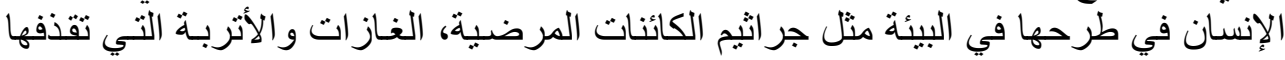

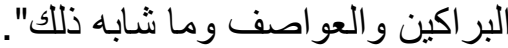

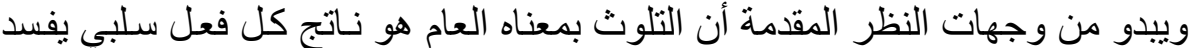

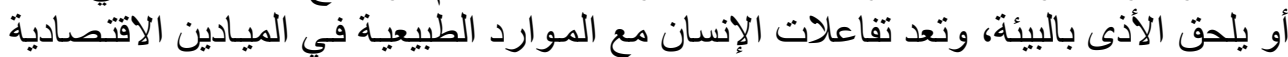

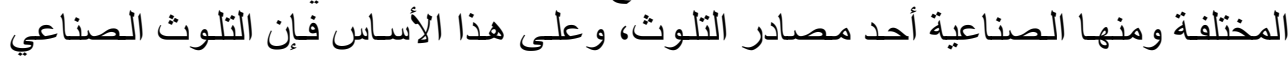

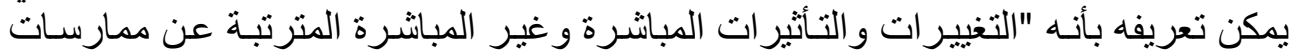

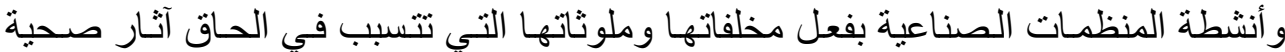

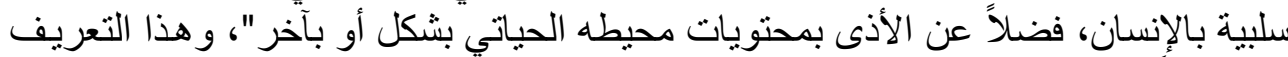

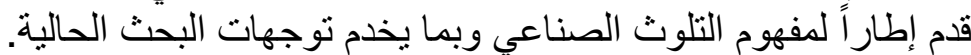

ب. تصنيفات الملوثات الصناعية

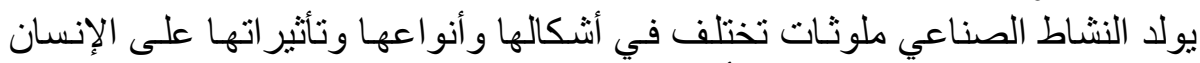

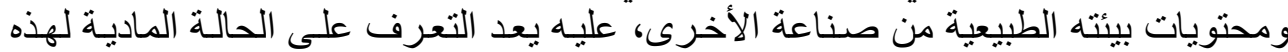

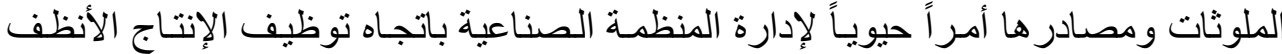

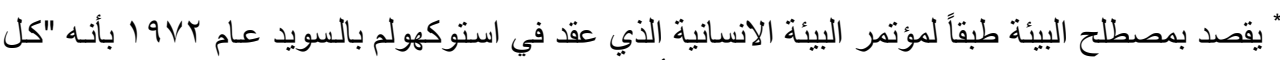

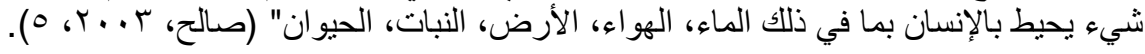




\section{النعمة وحمودي]}

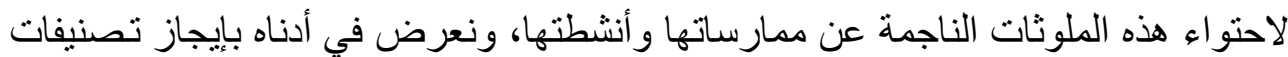

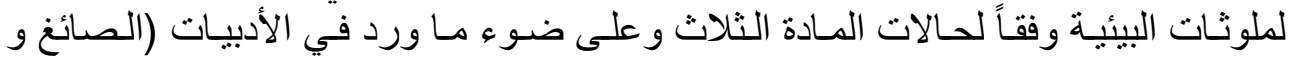

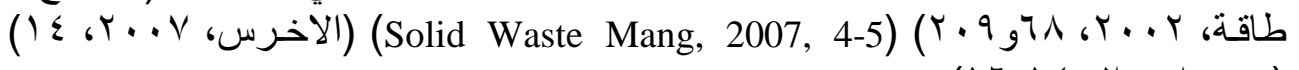

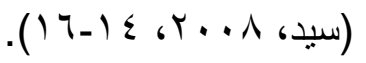

ا ـ الملوثات الغازية

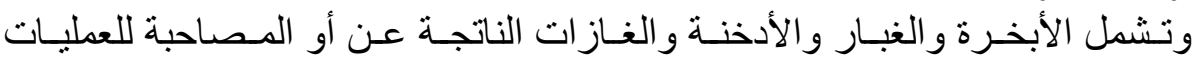

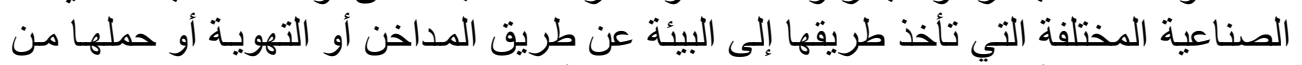

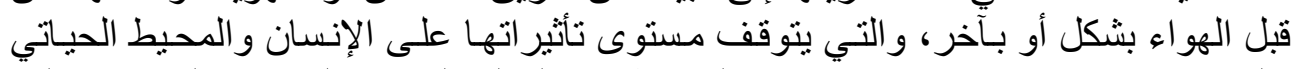

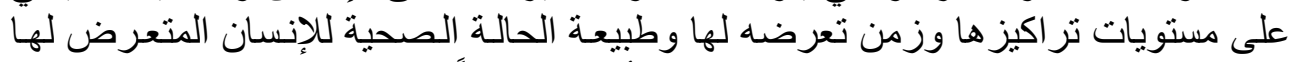

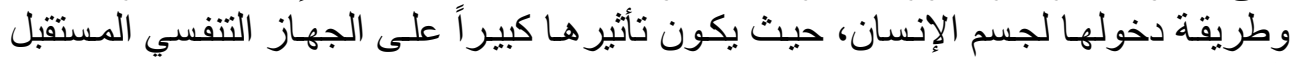

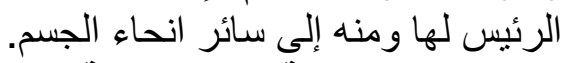

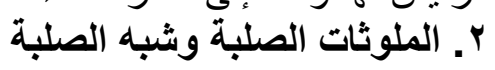

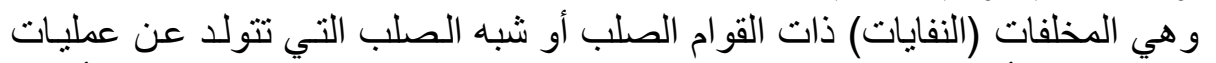

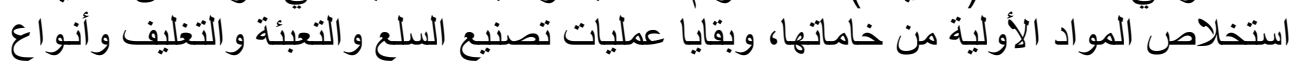

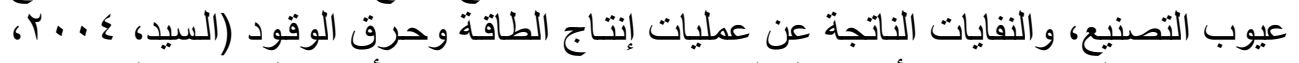

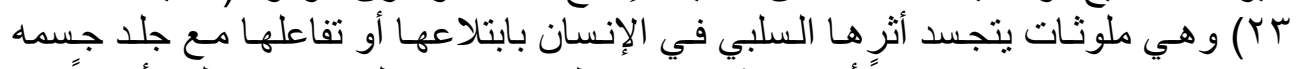

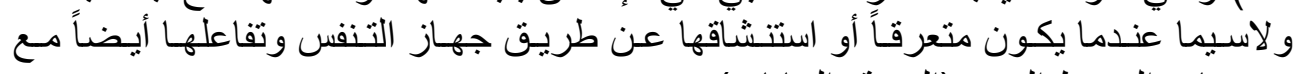

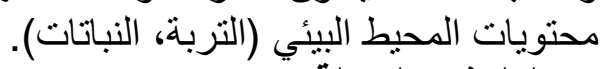
r. الملوثنات السائلة الئة

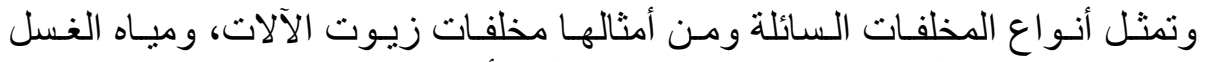

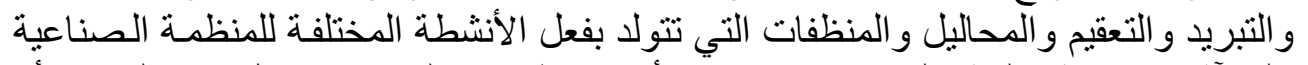

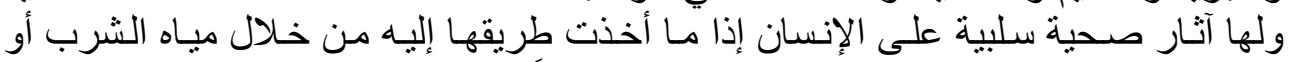

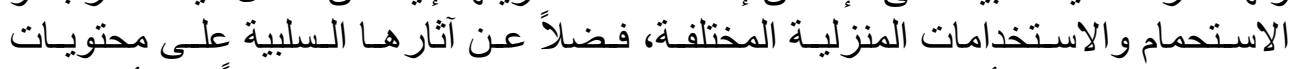

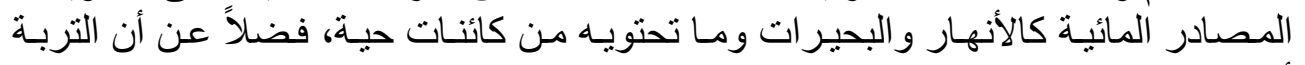

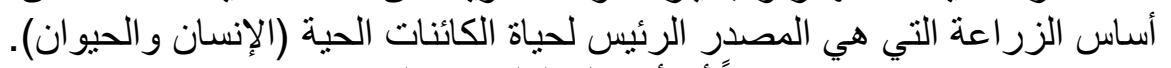

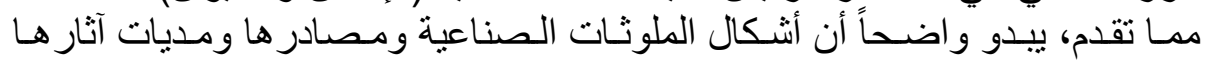

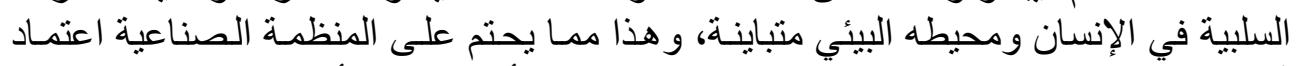

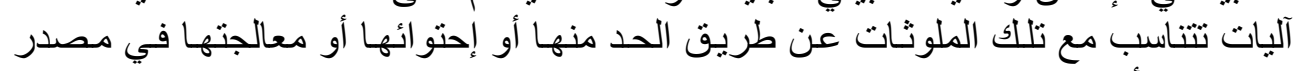
تكوينها ما أمكن.

\section{r. الإنتاج الأنظف- تأطير مفاهيمي

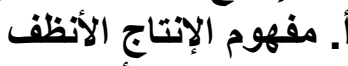

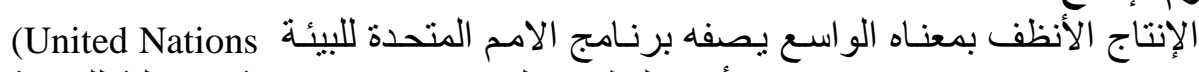
بأنه "التطبيق المستمر لإستر اتيجية متكاملـة للوقايـة (UNEP) Environmental Program) 
البيئية تطبق على العمليات والمنتجات بغرض زيـادة الكفاءة وتقليل المخاطر المؤثرة في

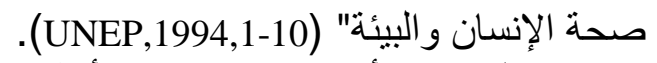

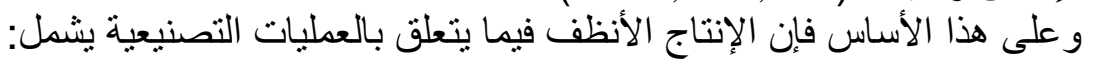

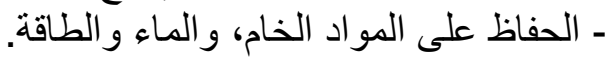
ـ ـ استيعاد المواد الخام السامة. ـ تقليص كمية وسمية جميع الانبعانات. - تقليص المخلفات في مصندر ها.

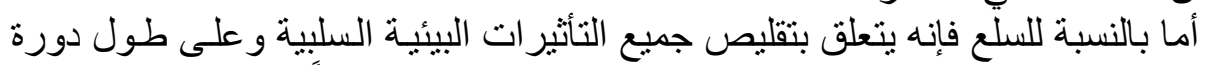

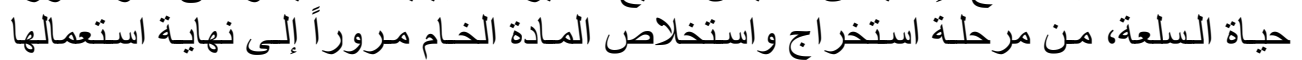

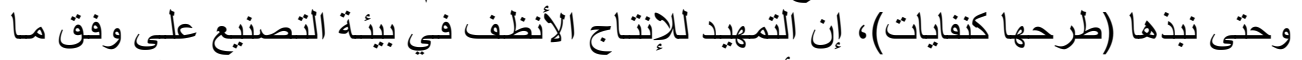

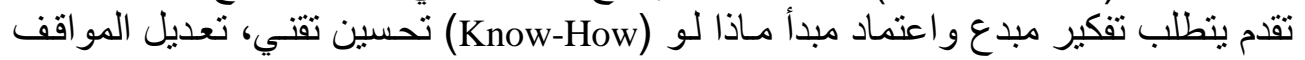

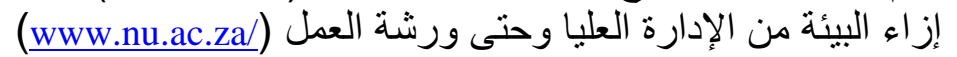

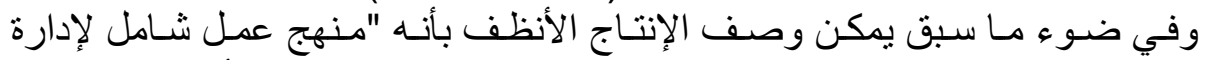

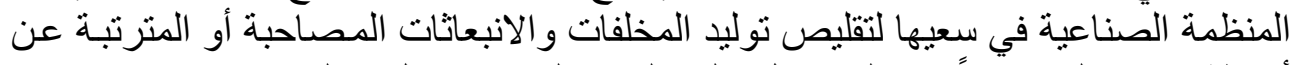

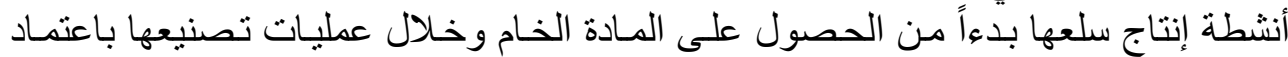

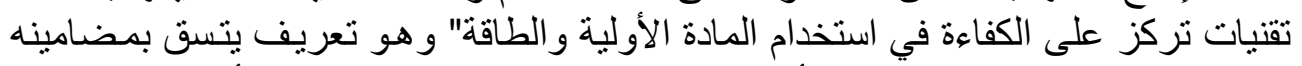

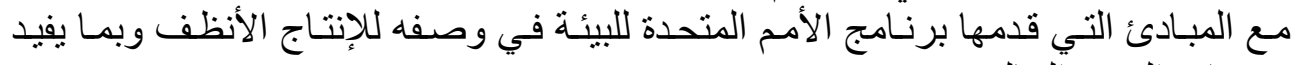
توجهات البحث الحالي.

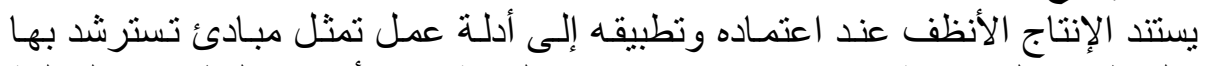

\section{ب. مبادئ الإنتاج الأنظف}

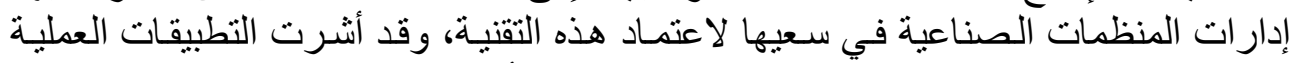

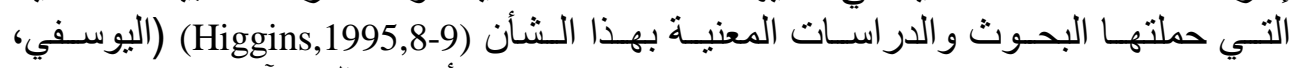

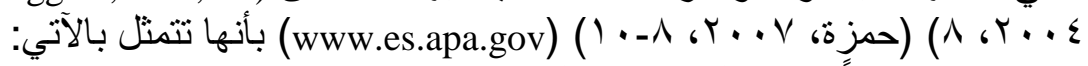

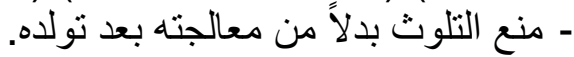
- ترشيد تصاميم السلع و العمليات الإنتاجية.

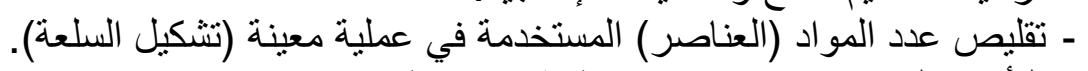

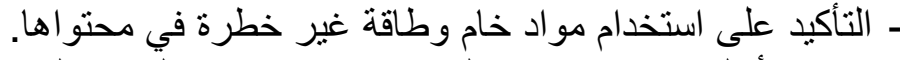

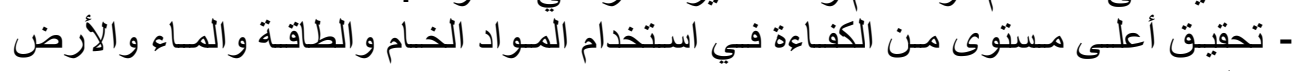

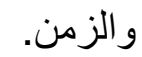

- تأمين التكامل الموقعي لعمليات الإنتاج مع المواد الخام والطاقة.

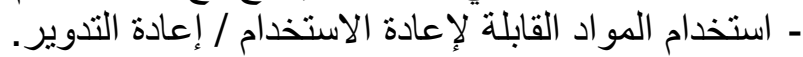

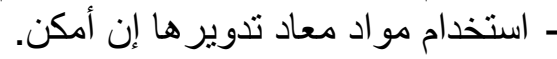

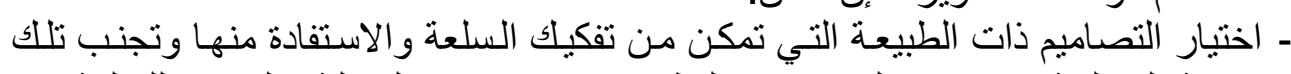

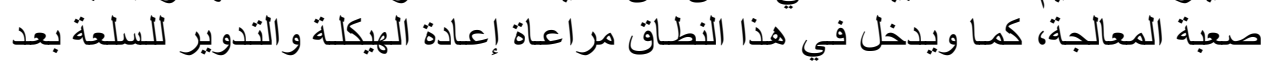

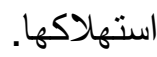
- التأكيد على استخدام مصدر الطاقة المتجدد أو بـرامج توفير الطاقة لتقليص الاستهلاك منها كاستخدام مياه تبريد الآلات لأغر اض اضل التدفئة. 


\section{النعمة وحمودي[VT]}

ـ استبدال المذيبات الكيمائية الخطرة ببدائل أخرى غير خطرة مثنل المذيبات المائية كتلك القابلة للتحلل الحيوي غير سامة أو الأقل سمية.

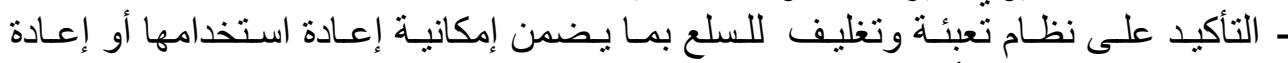
تدوير ها بعد استخدام أو استهلاك السلعة.

ت. المنافع التطبيقية للإنتاج الأنظف

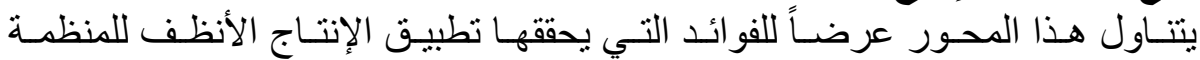

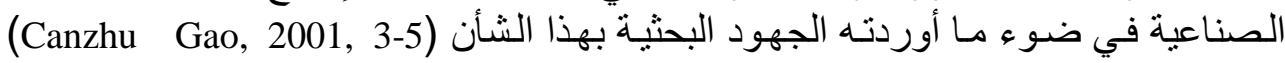

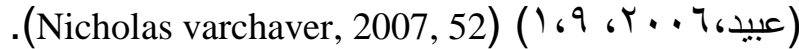

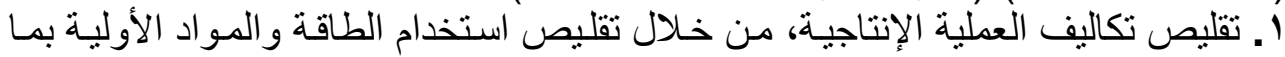

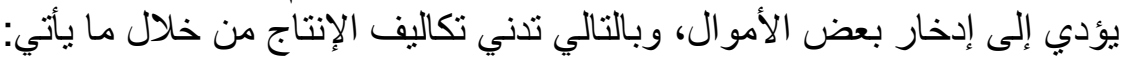

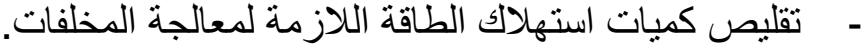
ـ - تقليص كميات الكيميائيات المطلوبة لمعالجة المخلفات.

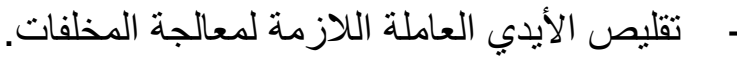

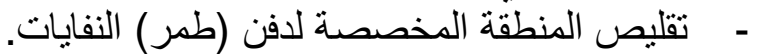

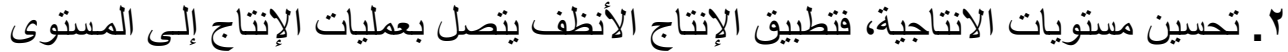
المثالي نتيجة وفورات الوقت وبالنتيجة زيادة الإنة الإنتاج.

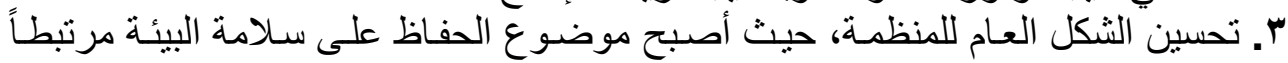
بأهداف المنظمات المعاصرة المنام

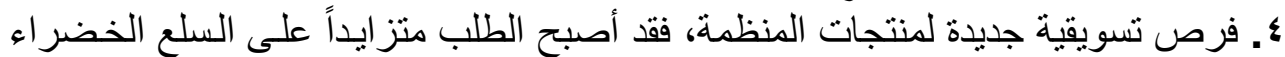

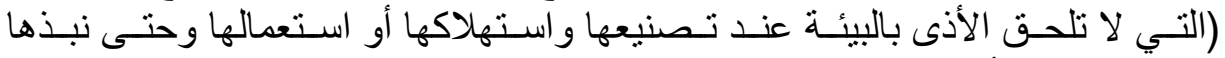

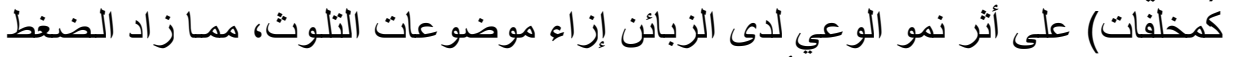

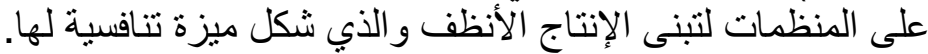

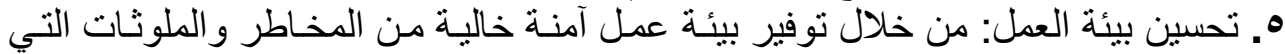
لها آثار سلبية على صحة الإنسان.

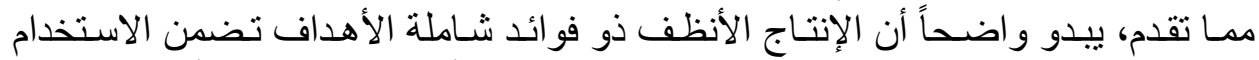
الامثل للموارد، وبما يعزز موقف المنظمة التنافسي وتحقق أعلى مستويات الأمسان للإنسان الإنسان بتفاعله مع محتويات بيئته.

\section{ث. متطلبات اعتماد الإنتاج الأنظف}

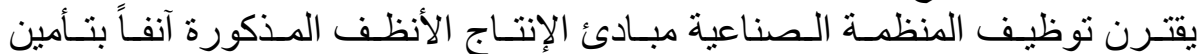

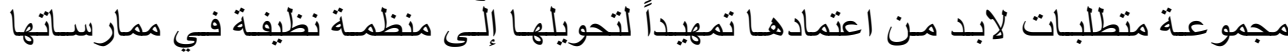

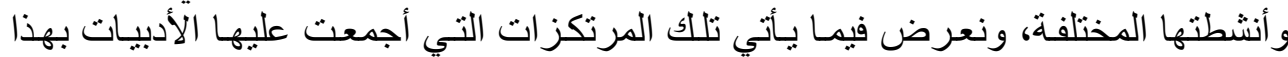

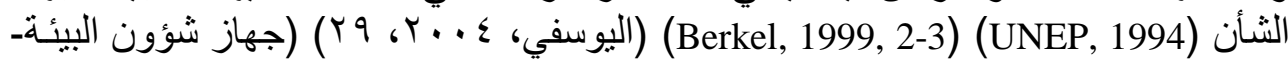

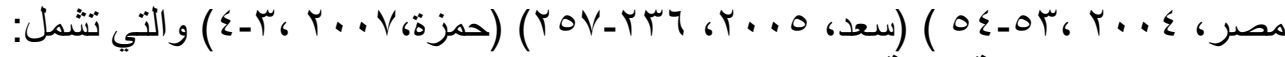

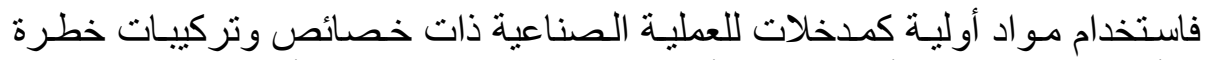

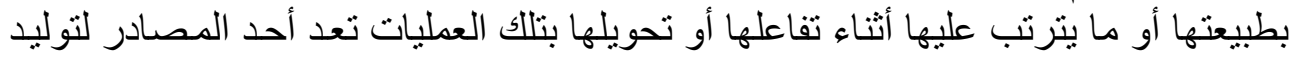

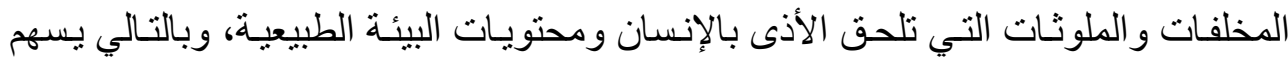


ترشيد استخدامها على نحوِ كبير في تقليص تولد هذه النفايات، أو من خلال توفير بدائل لها

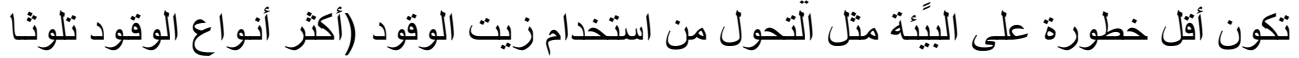

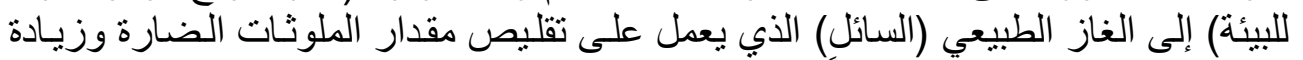

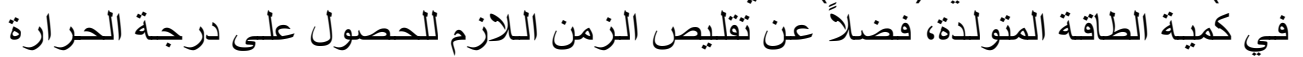

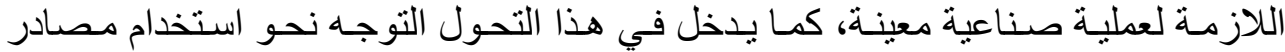
الطاقة المتجدة كاستخدام الطاقة الثنمسية أو طاقة الرياح.

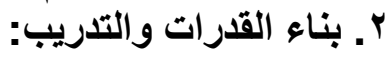

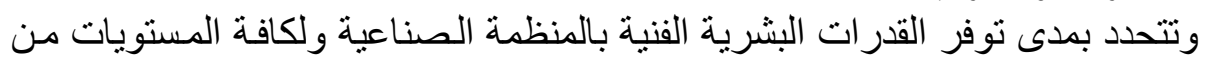

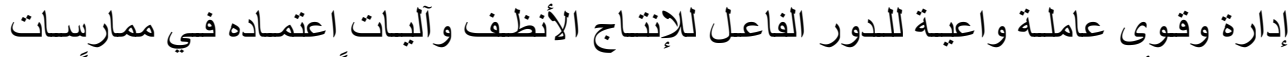

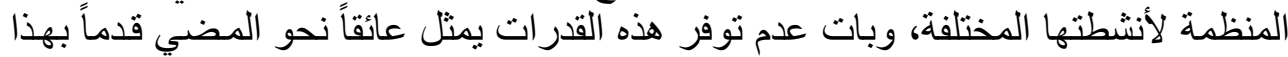

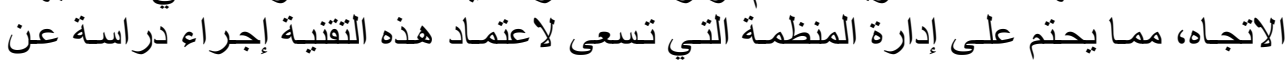

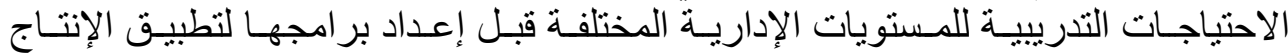

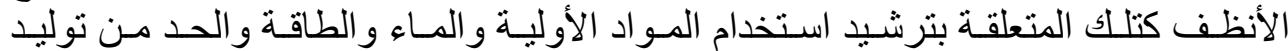
المخلفات و إجراءات الترتيب و النظافة لموقع العمل وخطط مو اجهة الطو ارئ.

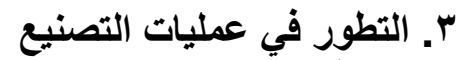

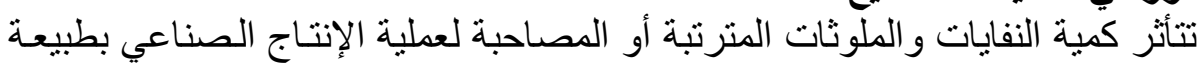

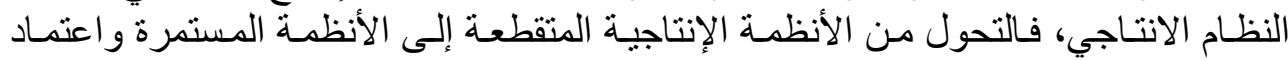

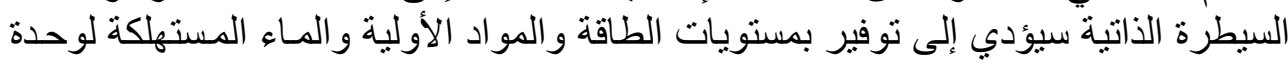

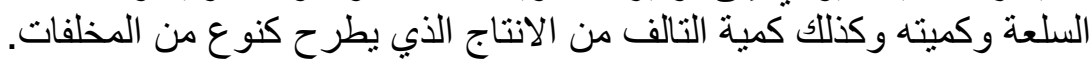

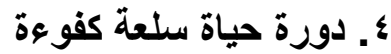

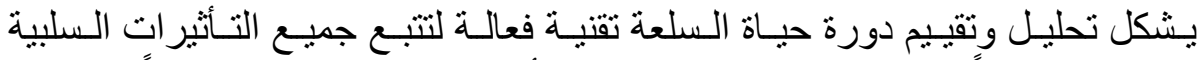

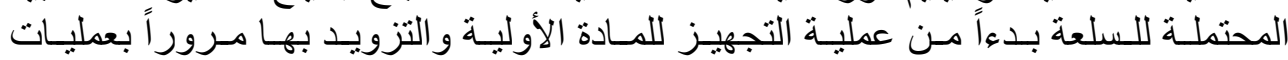

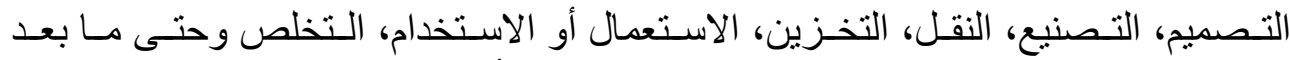

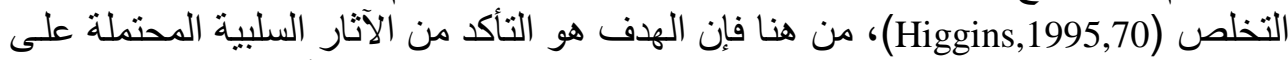

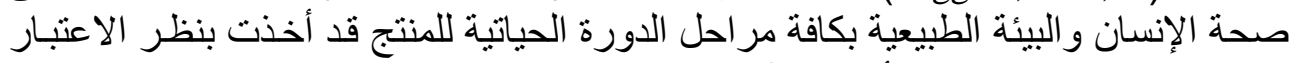

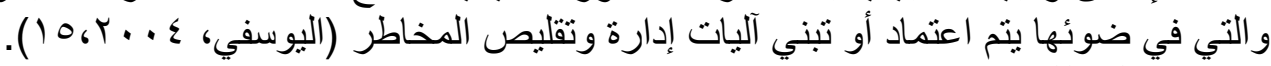

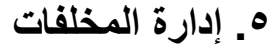

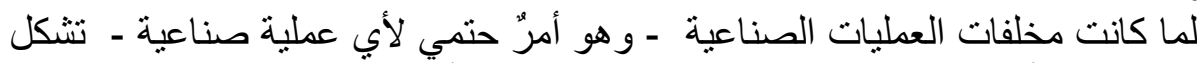

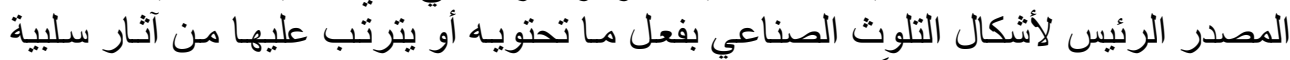

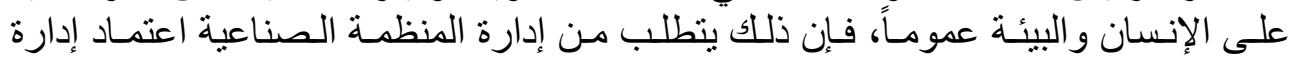

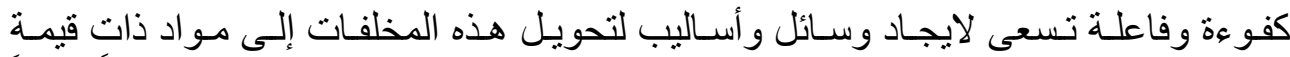

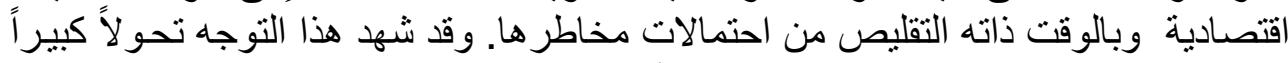

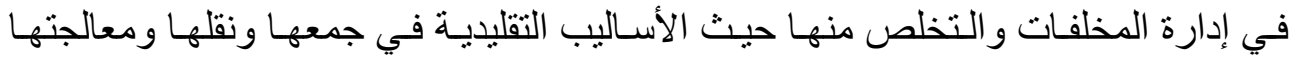

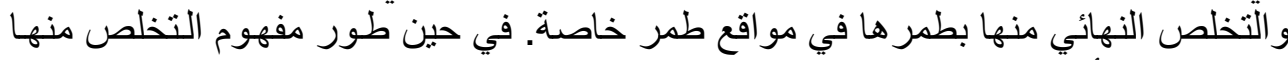

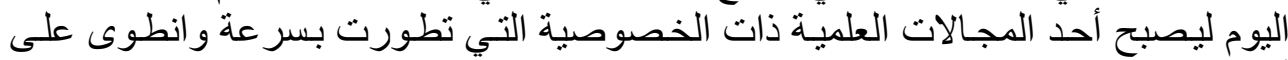

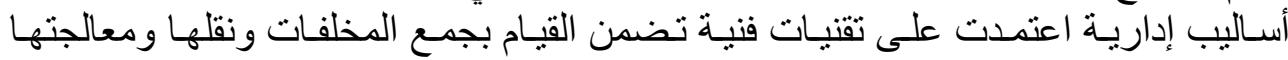

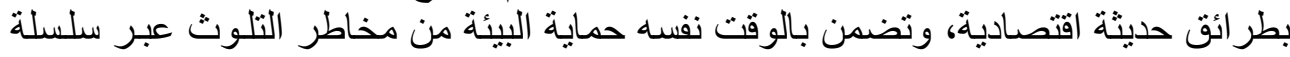

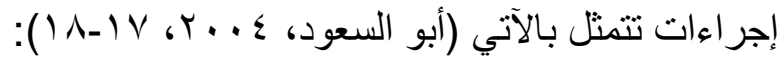




\section{النعمة وحمودي[vo]}

- استخدام مواد صديقة للبيئة في عمليات الإنتاج - أقل إلحاقاً بالأذى بالإنسان و البيئة على طول دورة حياة السلعة -.

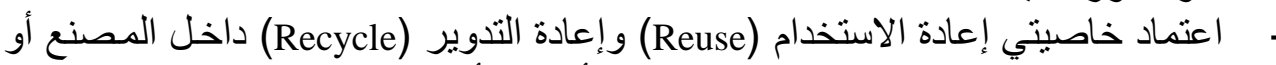
خارجه للمخلفات و الاستفادة منها في عمليات أو سلع أخرى أخرى.

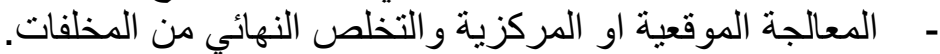

7. اعتماد تقتيتي إعادة الاستخدام وإعادة التدوير (Recycle \& Reuse)

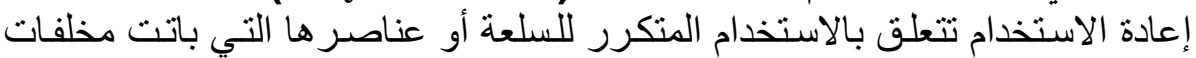

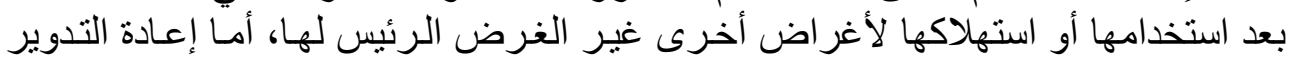

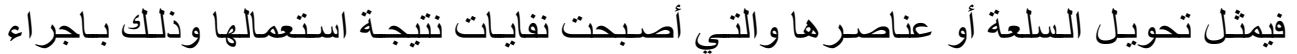

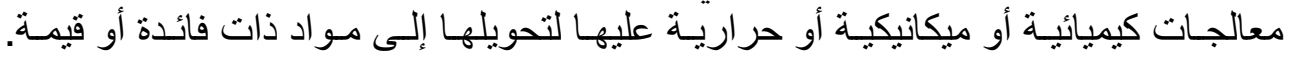

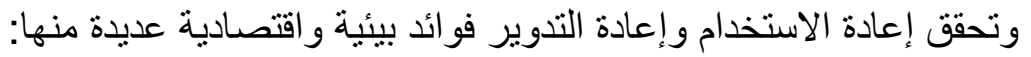

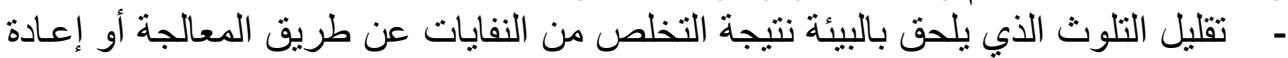

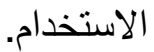
- - - الاستخدام الأمثل للموارد ارد الطبيعية و الطاقة.

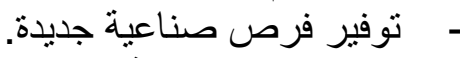

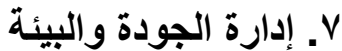

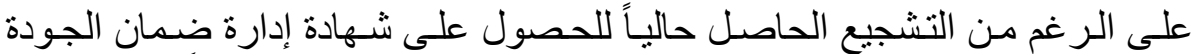

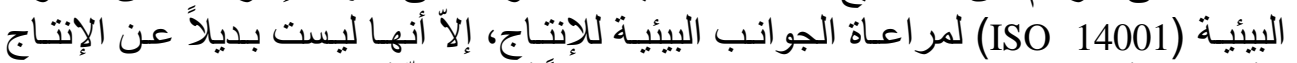

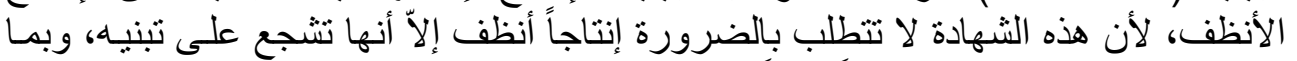

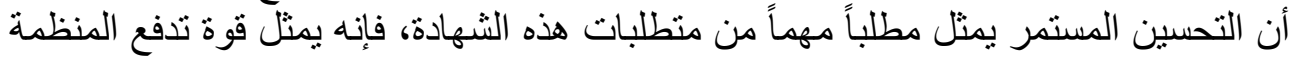

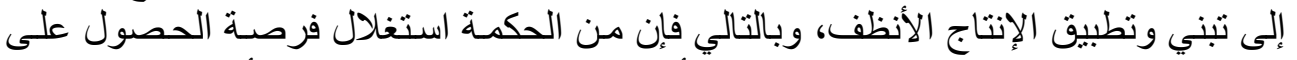

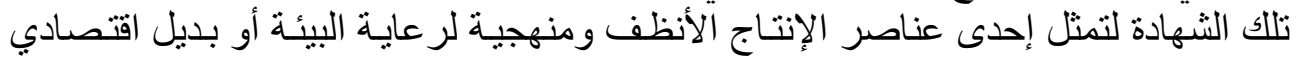

\section{ج. معوقات التحول لتطبيق الإنتاج الأنظف}

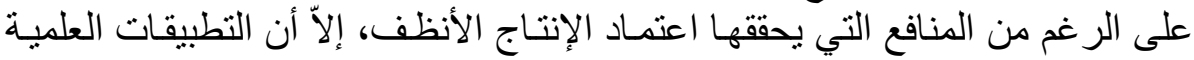

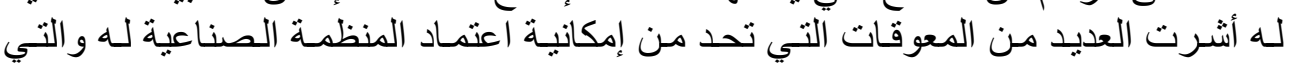

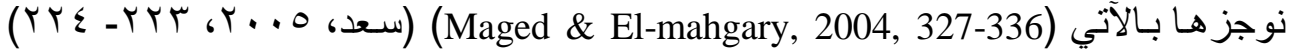

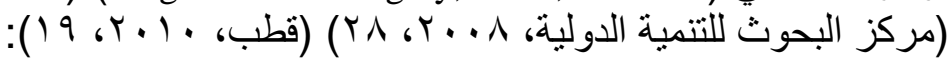

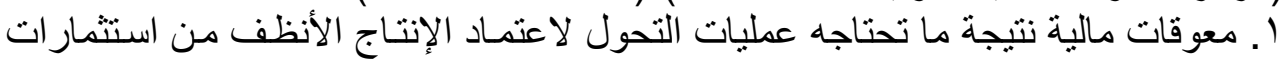

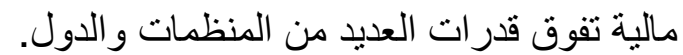

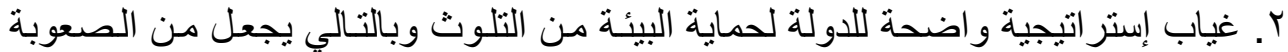
الحصول على الإنتاج الأنظف.

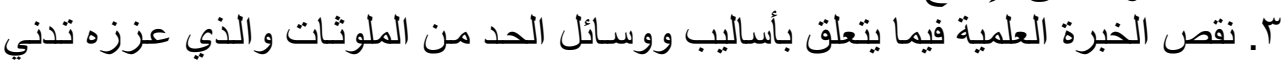

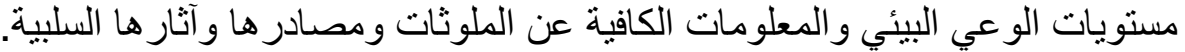

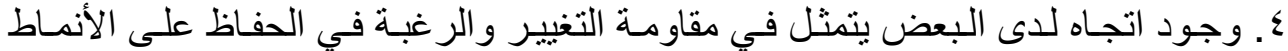

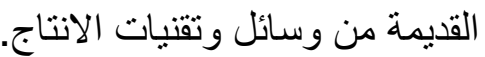

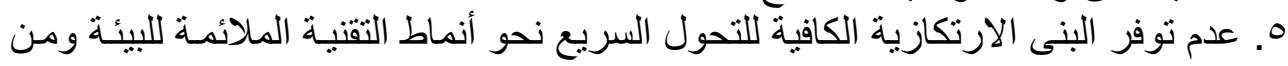




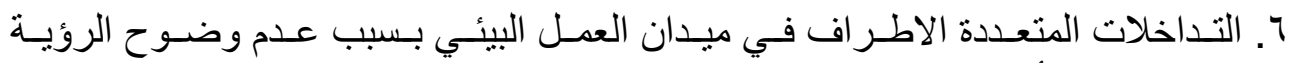
لضرورات وأولويات الحماية من مخاطر التلوث واستر التيجياتها.

\section{ثالثاً الإطار التطبيقي

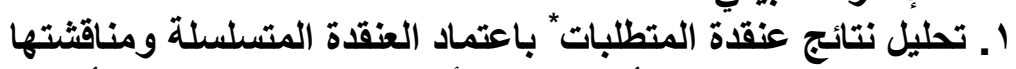

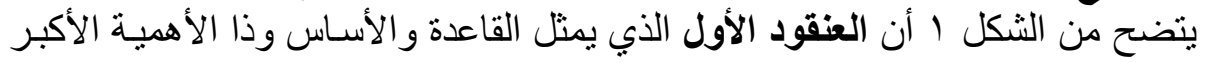

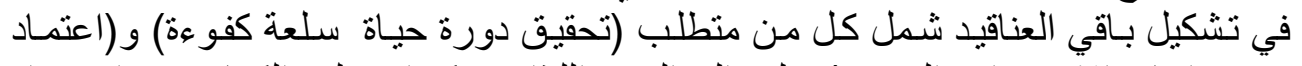

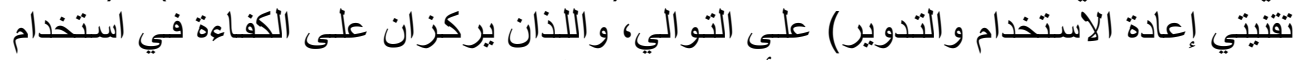

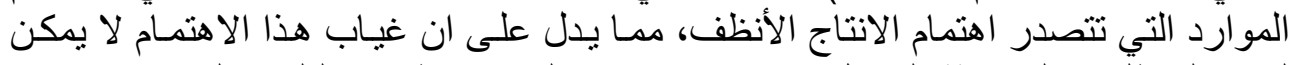

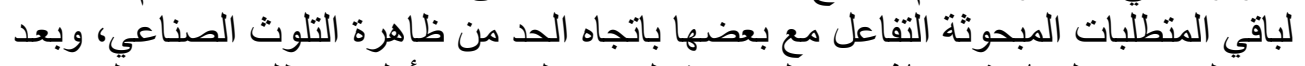

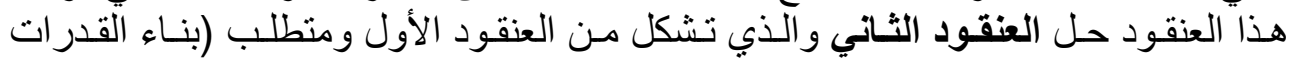

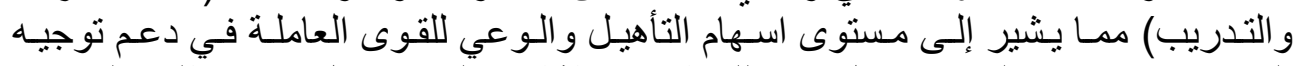

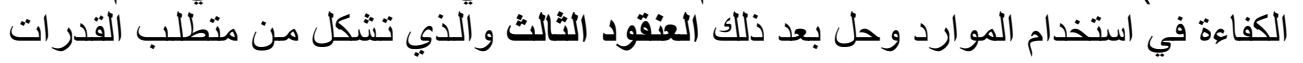

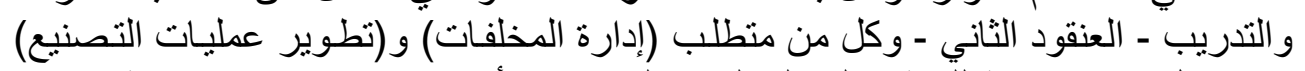

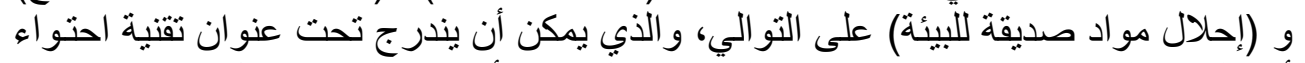

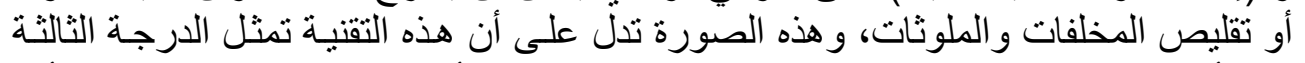

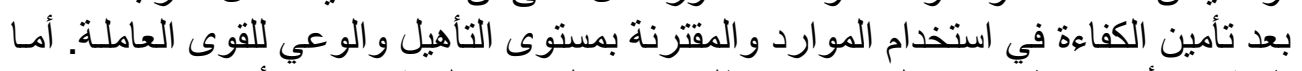

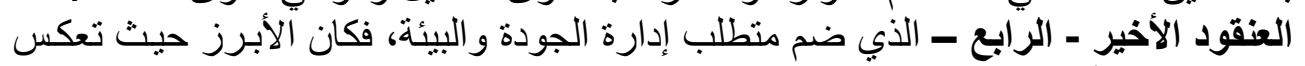

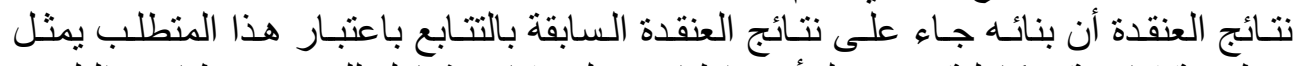

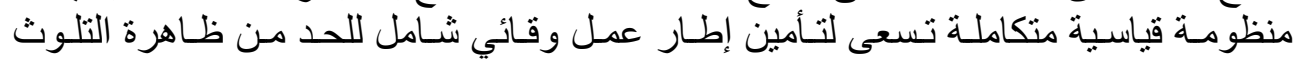

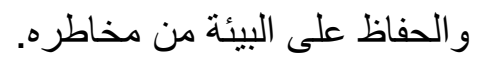

Dendrogram using Centroid Method

Rescaled Distance Cluster Combine

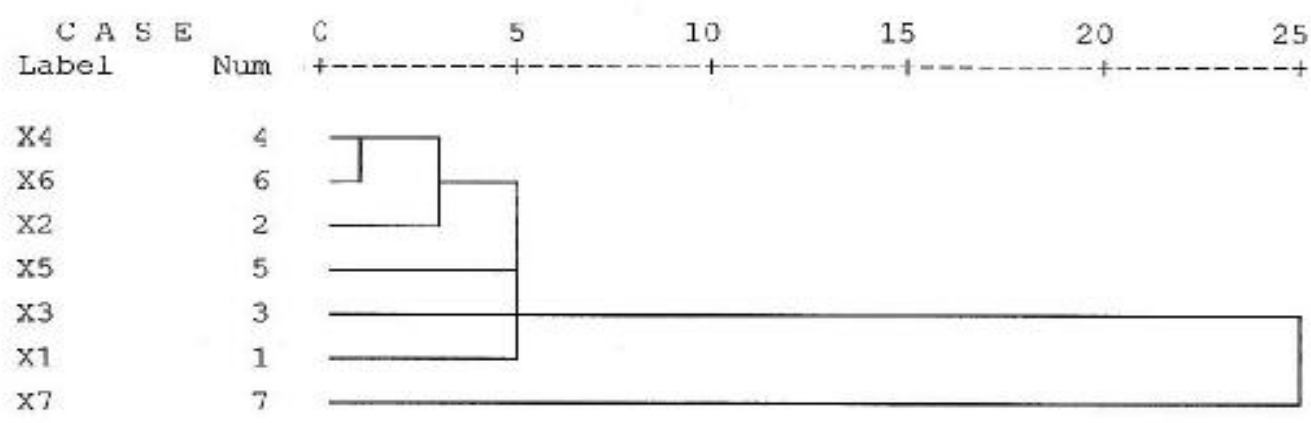

* يقصد بها حيثما وردت فصاعداً منطلبات اعتماد الإنتاج الأنظف اختصار ا. 


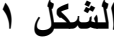

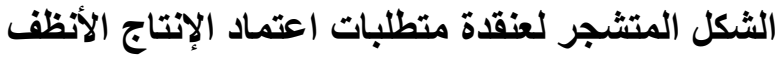

المصدر: من إعداد الباحثان بالاعتماد على نتائج البرمجية الإحصائية (SPSS).

مما تقدم، يلحظ أن العنقدة أعلاه للمتطلبـات التي اعتمدت القيمـة الرقمية لكل متطلب

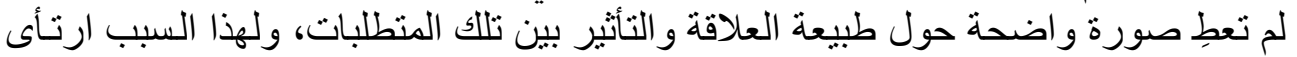

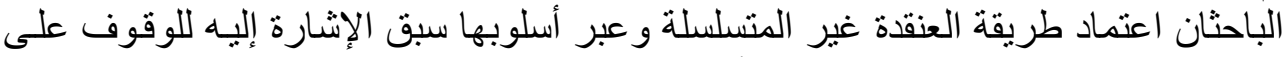

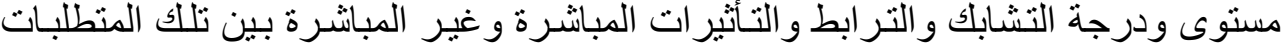

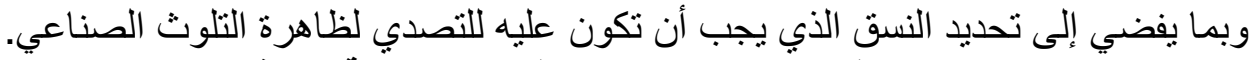

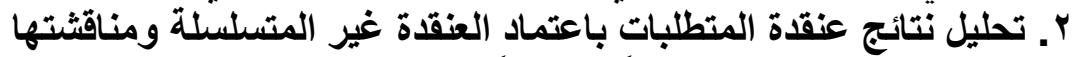

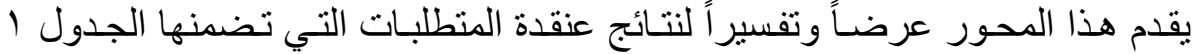
باعتماد أسلوب (K-Mean Clustering) ومن خلامل محورين:

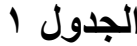

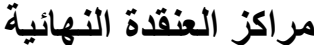

\begin{tabular}{|c|c|c|c|c|}
\hline \multirow{2}{*}{ المتطلبات } & \multicolumn{4}{|c|}{ رقم العنقود* } \\
\hline & $T$ & $r$ & $r$ & $\varepsilon$ \\
\hline إحلال مو اد صديقة للبيئة & 1.91 & ร.7 & r.9V & $T .1 \varepsilon$ \\
\hline بناء القدرات و التدريب & E.rT & ¿.vo & $r .79$ & $r . \leqslant r$ \\
\hline التطوير في عمليات التصنيع & r.Vo & $\varepsilon .0$ & $r . V \varepsilon$ & r.9. \\
\hline تحقيق دورة حياة سلعة كفو عة & $\varepsilon .$. & $\varepsilon .7$. & r.vo & ד. \\
\hline إدارة المخلفات & $\varepsilon \ldots$ & $\varepsilon .1 T$ & $r . Y$ & r.00 \\
\hline اعتماد تقنيتي إعادة الاستخدام و التدوير & r.Vo & $\varepsilon . V_{0}$ & $r . v 9$ & T.10 \\
\hline ادارة الجودة و البيئة & $r .7$. & $r_{\varepsilon . \varepsilon}$ & T.TV & T.07 \\
\hline
\end{tabular}

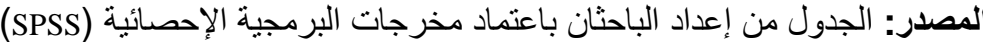

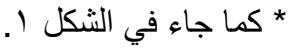

أ. عرض وتفسير نتائج العنقدة على أساس مستوى مشاركة كل متطلب في العناقيد المشكلة (المتطلبات الأكثر تقارباً)

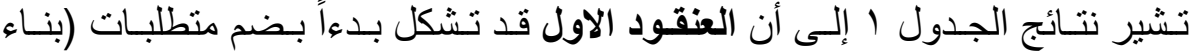

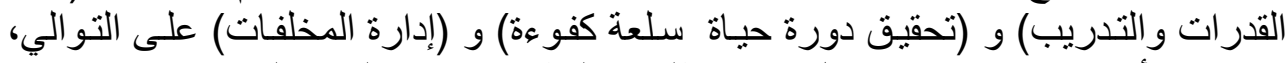

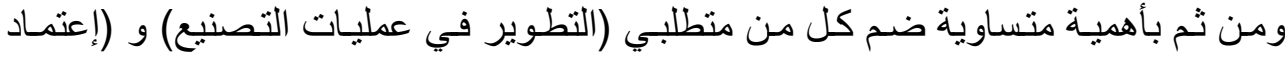

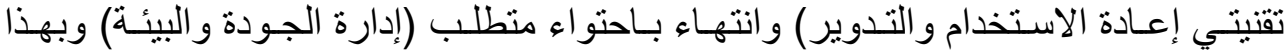

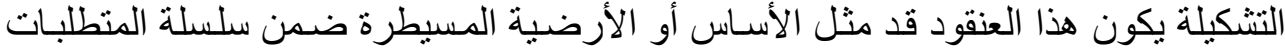

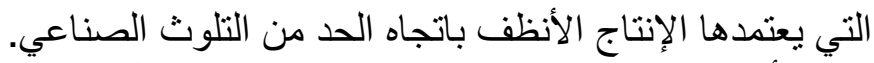

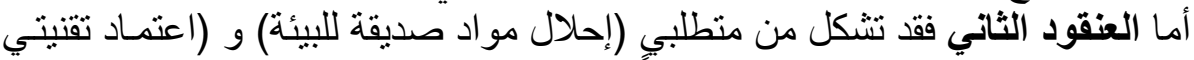

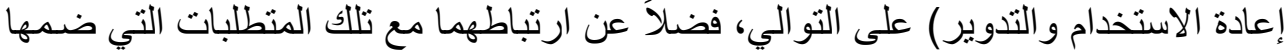

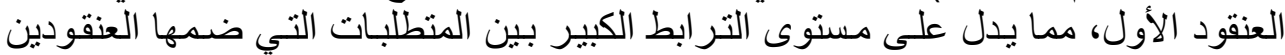

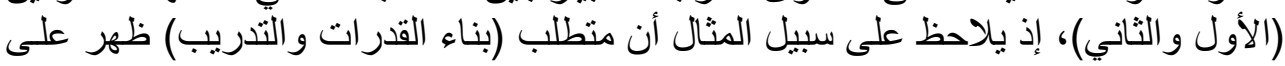




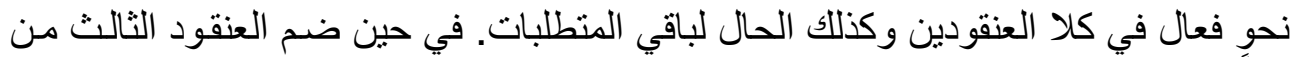

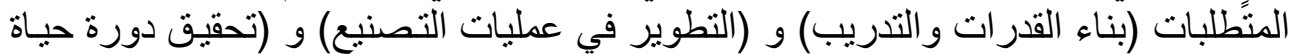

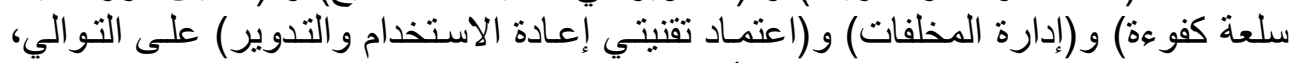

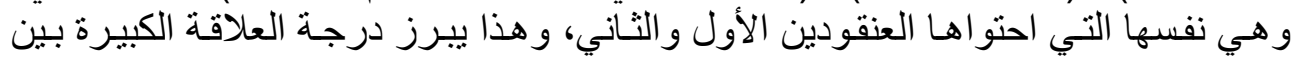

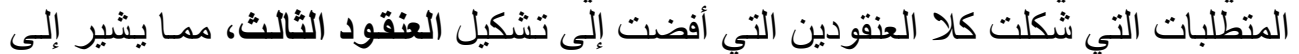

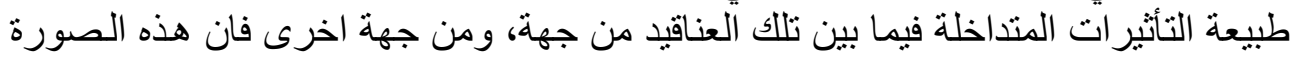

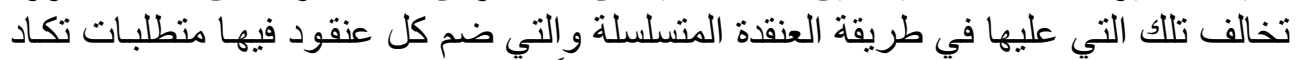

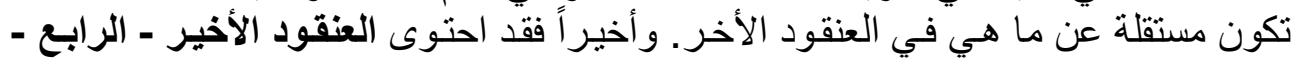

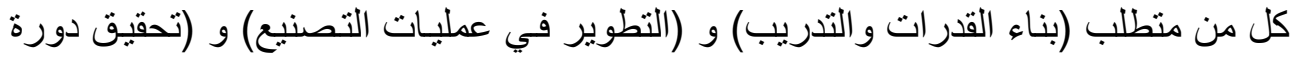

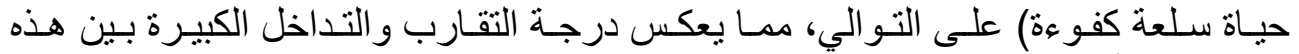
المتطلبات وأبعاد الدور الذي تؤديه إز اء الحد من ظاهرة التلوث الصناء داعي.

ب. عرض وتفسير نتائج العنقدة على أسساس مستوى مشاركة كل منطلب في العناقيـ المشكلة اعند

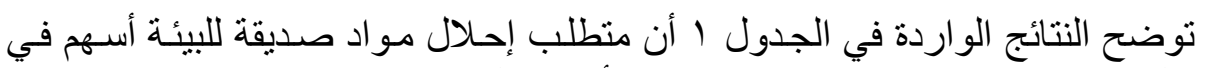

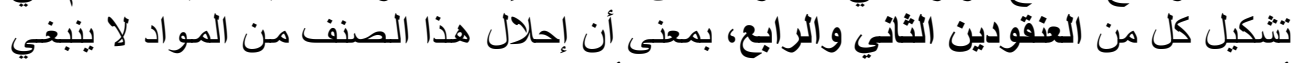

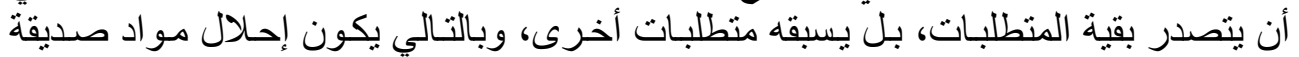

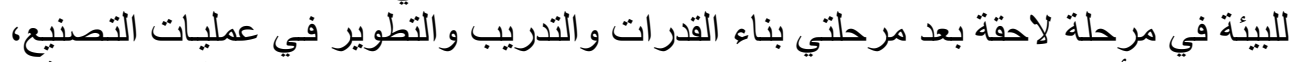

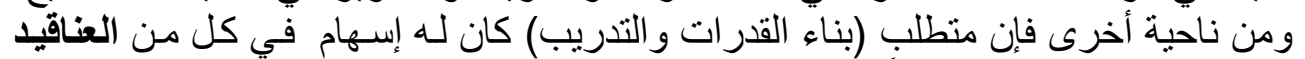

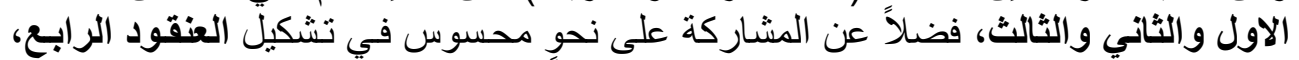

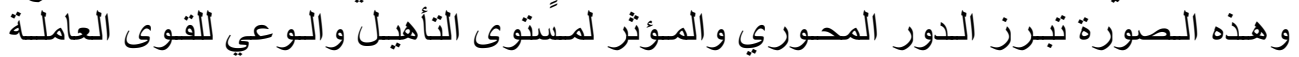

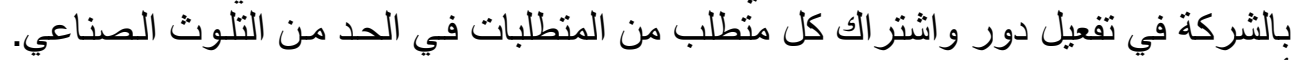

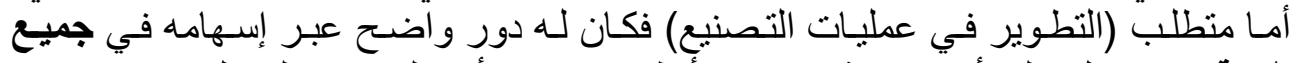

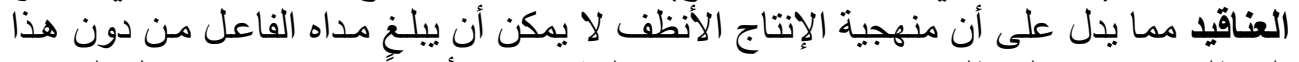

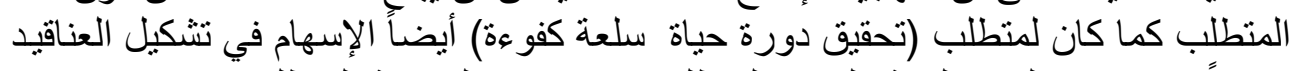

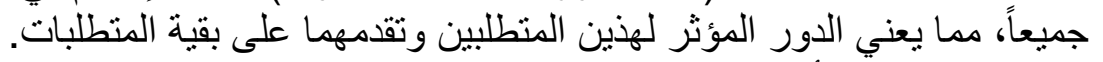

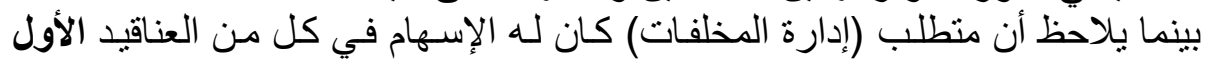

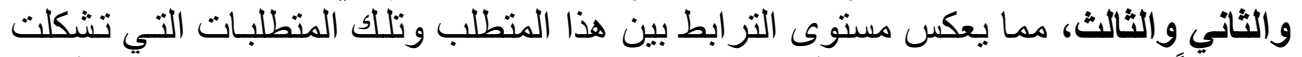

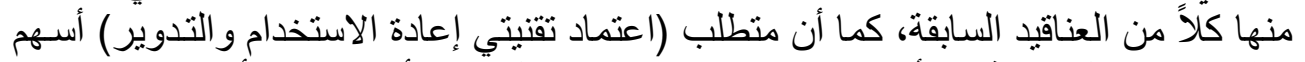

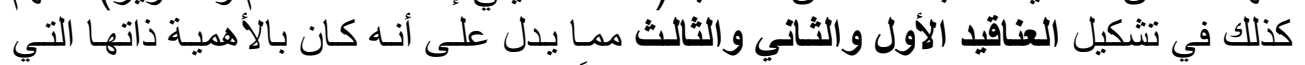

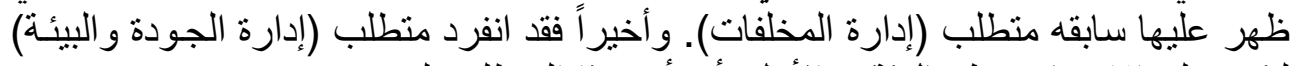

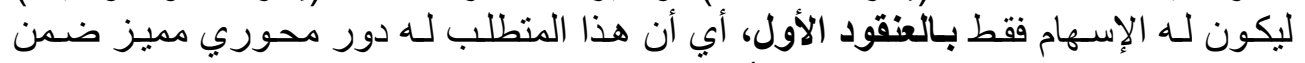

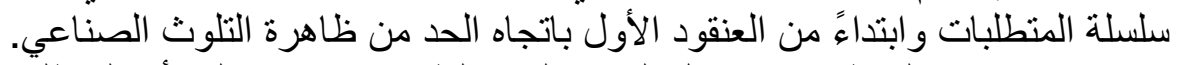

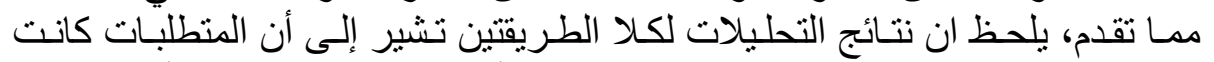

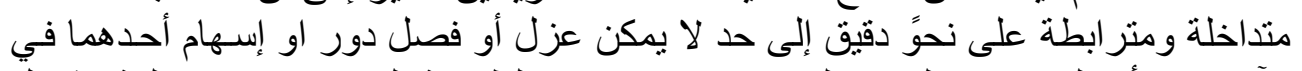

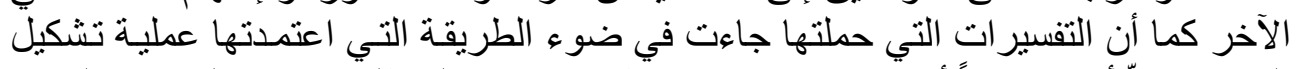

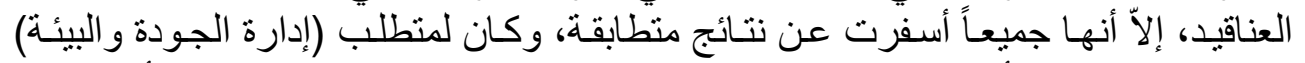

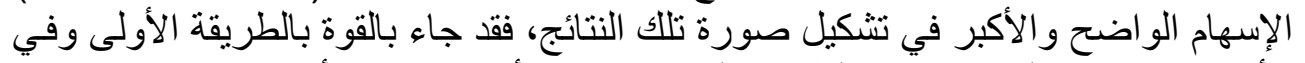

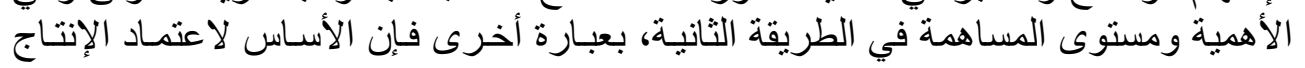


الأنظف عبر سلسلة المتطلبات المبحوثة كان محور ها متطلب إدارة الجودة و البيئة لمبررات أشرتها التحليلات أعلاه.

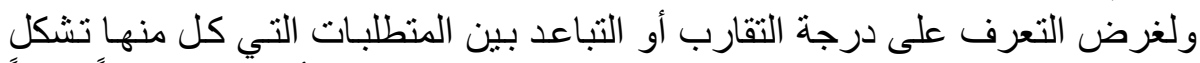

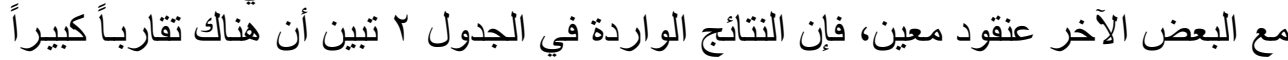

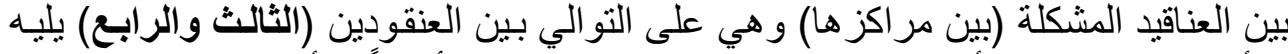
(الأول والثالث) ثم (الأول والر ابع) وبعده (الثاني والثالث) و وأخير أ (الأول والثاني).

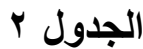

المسافة بين مراكز العنقدة النهائية طبقا لأسلوب (K-mean Clustering)

\begin{tabular}{|c|c|c|c|c|}
\hline العنقود & 1 & r & $r$ & $\varepsilon$ \\
\hline 1 & - & r. $79 \mathrm{~V}$ & $1 . v \leqslant \varepsilon$ & T.MA \\
\hline r & r. $79 V$ & - & $r .7 \leq 7$ & T. $\leqslant 7 \leqslant$ \\
\hline r & $1 . V \leq \varepsilon$ & $r .7 \leq 7$ & - & $1 . r \cdot \varepsilon$ \\
\hline$\varepsilon$ & Y.TY & $r . \leqslant 7 \leqslant$ & 1.r. & - \\
\hline
\end{tabular}

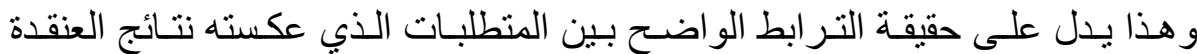

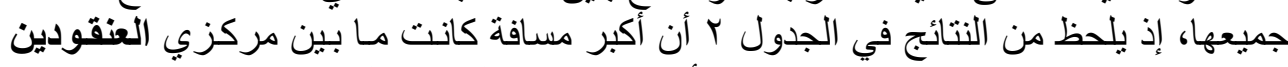

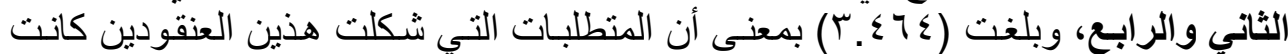

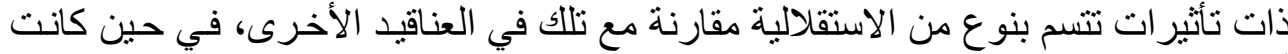

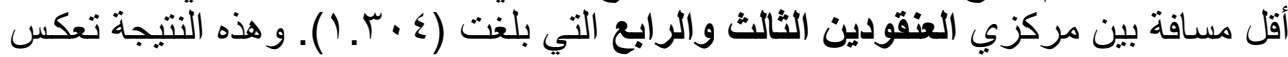

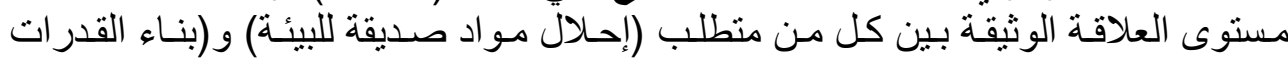

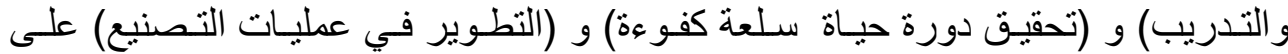

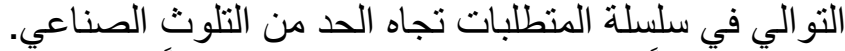

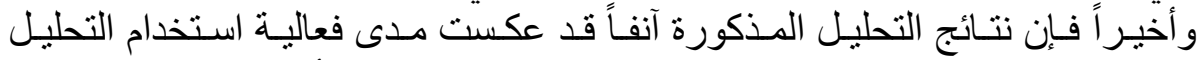

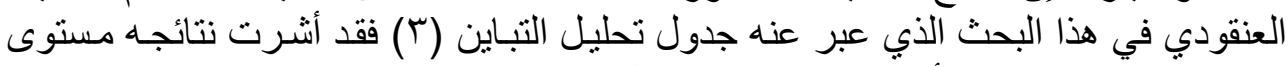

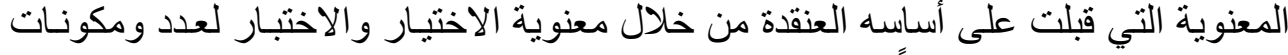

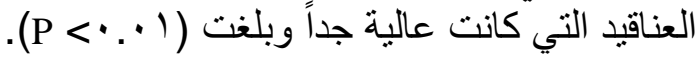

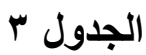

تعليل التباين (ANOVA) لنتائج العنقدة

\begin{tabular}{|c|c|c|c|c|c|c|}
\hline \multirow{2}{*}{ المتطلبات } & \multicolumn{2}{|c|}{ العنقود } & \multicolumn{2}{|c|}{ الخطأ } & \multirow{2}{*}{ الجدولية } & \multirow{2}{*}{ المستوى المتوية المعتية } \\
\hline & التباين & الحرجة & التباين & الحرجة & & \\
\hline احلال مو اد صديقة للبيئة & I.VT. & r & .111 & r) & 1 & $\because \cdots$ \\
\hline بناء القدر ات و التدريب & $.9 \vee$. & r &. .194 & r) & $0 . \cdot \varepsilon$ & $\because \cdots 9$ \\
\hline
\end{tabular}




\begin{tabular}{|c|c|c|c|c|c|c|}
\hline \multirow{2}{*}{ المتطلبات } & \multicolumn{2}{|c|}{ العنقود } & \multicolumn{2}{|c|}{ 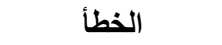 } & \multirow{2}{*}{ الجدولية } & \multirow{2}{*}{ المستوى المتمية } \\
\hline & مربع & الدرجة & مالتبع & الدرجة & & \\
\hline التطوير في عمليات التصنيع & . זיז. & r & $\cdot . \leqslant \leq 1$ & r) & $\cdot \wedge^{\wedge}$ & $\because \leqslant 99$ \\
\hline تطوير دورة حياة سلعة كفو عة &. V07 & r & .111 & r) & $7 . \leqslant 1$ &.$\ldots r$ \\
\hline ادارة المخلفات & $1 . \leqslant 10$ & r & $.1 \leq r$ & r) & $1 \cdot . \leqslant \leq$ & $\because \cdots$ \\
\hline اعتماد تقنيتي اعادة الاستخدام & $1.9 \wedge \mathrm{V}$ & r & $.1 T$. & r) & $10 . Y \Lambda$ & $\because \cdots$ \\
\hline ادارة الجودة و البيئة & .771 & r & rTr & r) & 0.7 & $\because \cdots$ \\
\hline
\end{tabular}

المصدر: الجدول من إعداد الباحثان بالاعتماد على مخرجات البرمجية الإحصائية (SPSS)

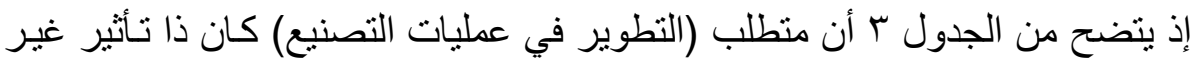

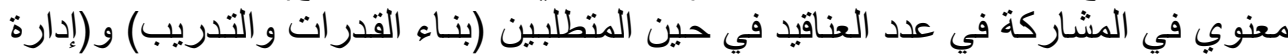

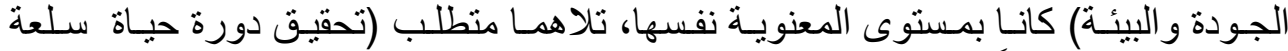

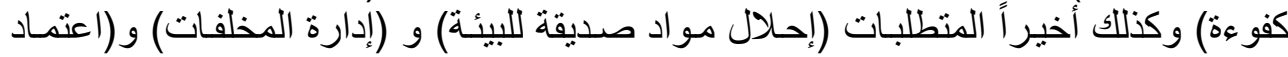

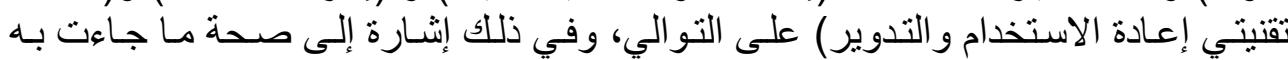
الفرضية التي اعتمدها البحث التي تنص على (تلبـاين الأهمية النسبية التي توليها التها الشركة المبحوثة لمتطلبات اعتماد الإنتاج الأنظف).

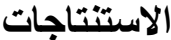

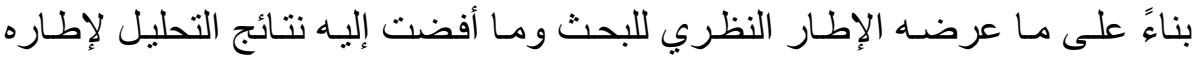
الميداني، فقد توصل البحث إلى مجمو عة استنتاجات يمكن حصر ها باليآلآتي:

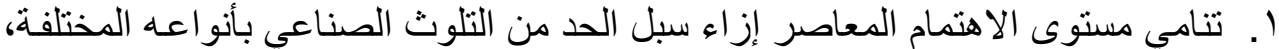

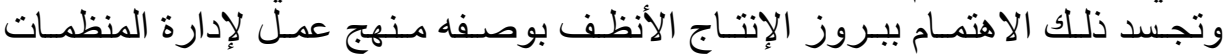

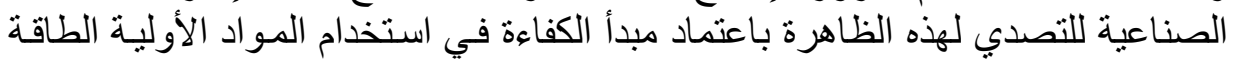

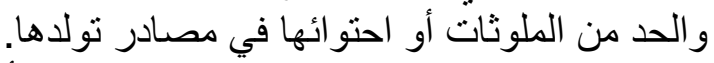

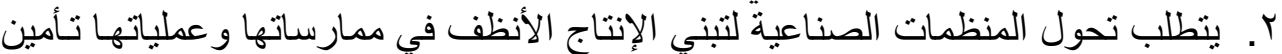

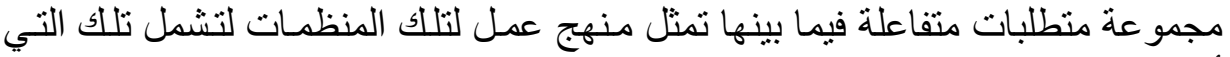

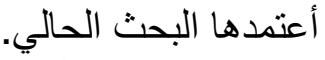

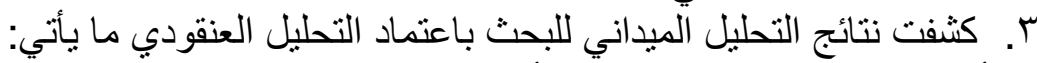

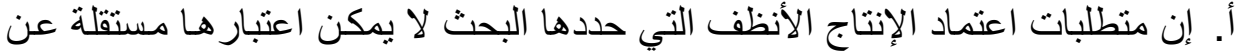

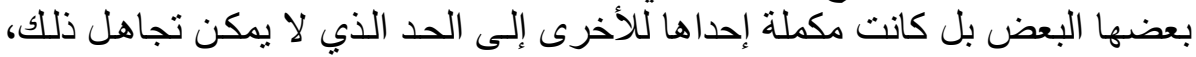

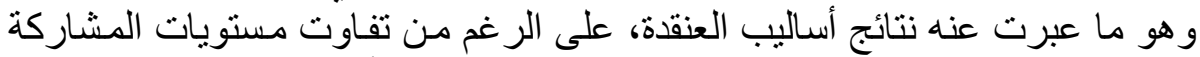

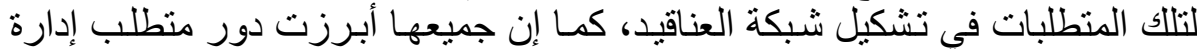
الجودة والبيئة في تتكيل منهج الإنتاج الأنظف و أساس اعند اعنماده. 


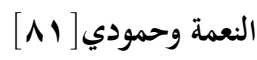

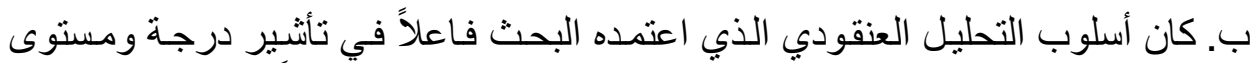

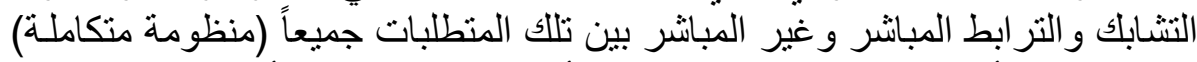

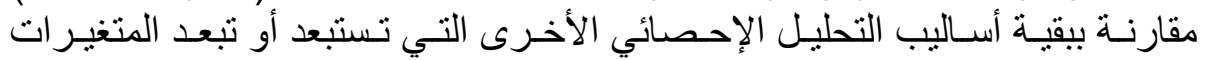

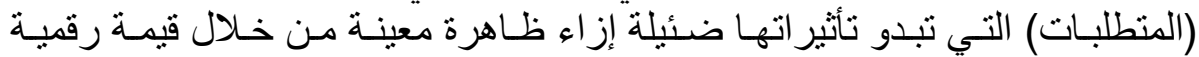

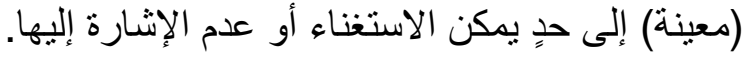

في ضوء مات اتم تقديمه من استتناجات يقام البحث مجمو عـة مقترحات يمكن أن تسهرم

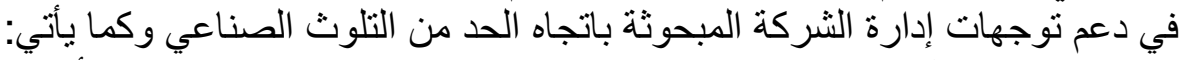

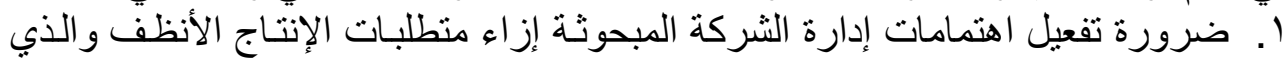

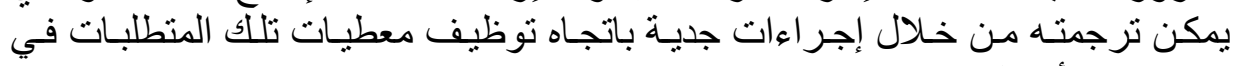
ممارستها و أنشطتها.

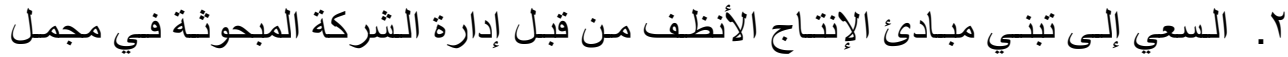

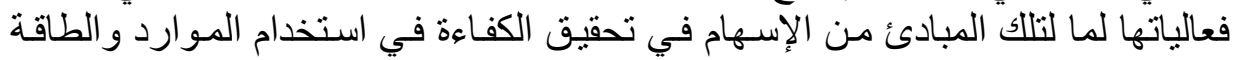

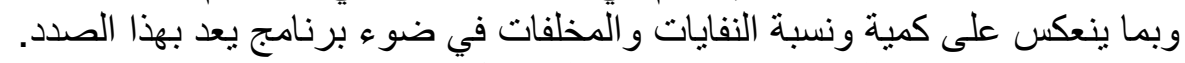

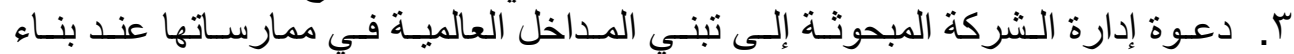

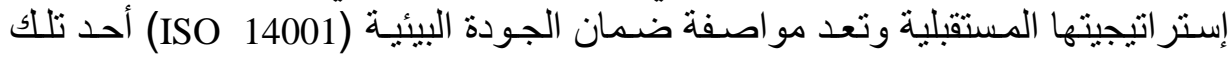

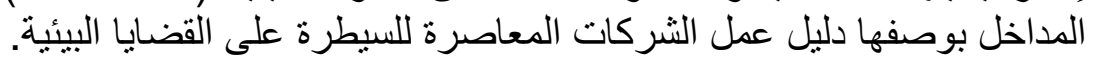

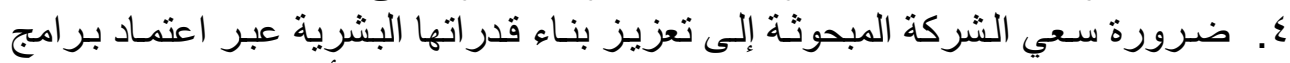

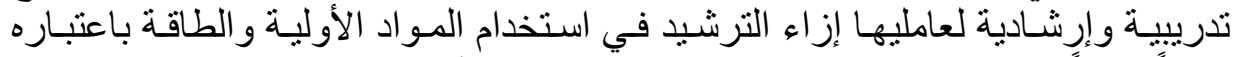

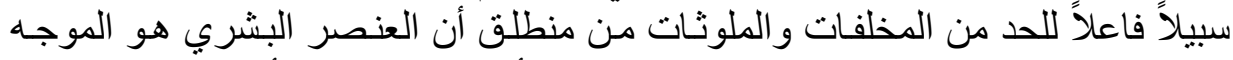

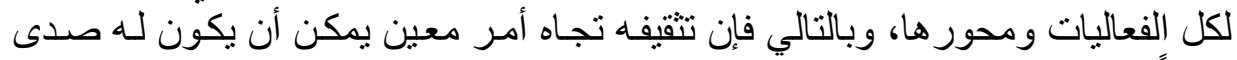

\section{المراجِ المع اجع باللغة العربية}

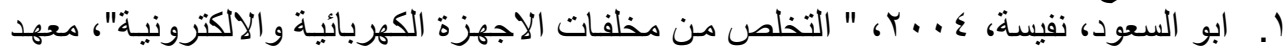

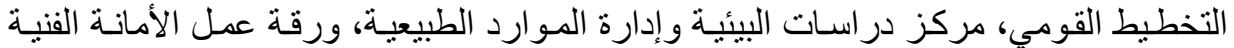

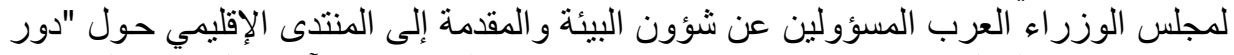

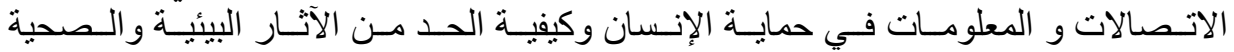

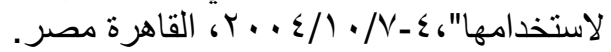

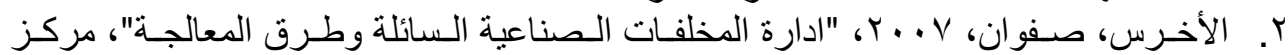

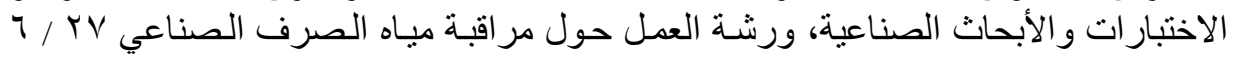

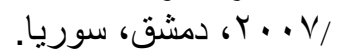

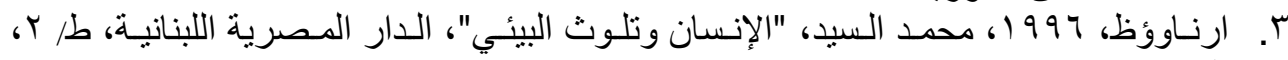

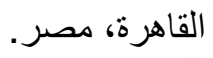

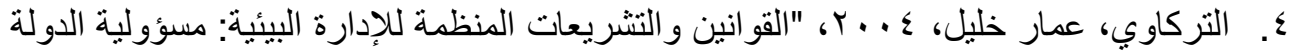

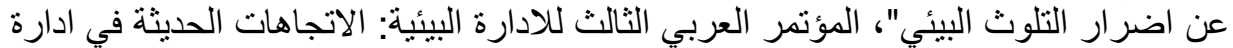

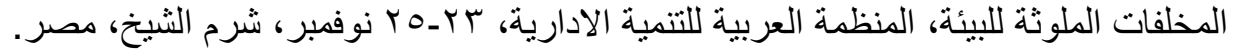




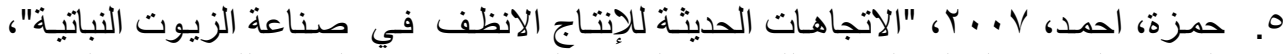

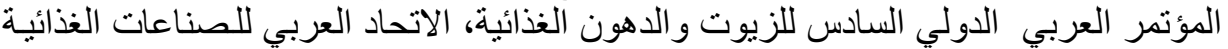

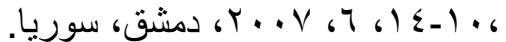

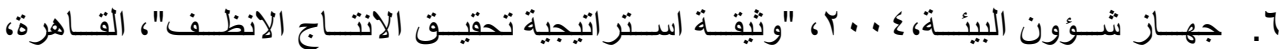
مصر

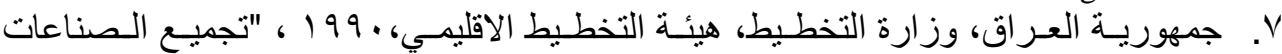
الملوثة و اثره في حماية وتحسين البئية البئة".

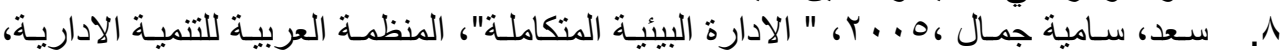

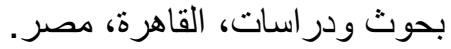

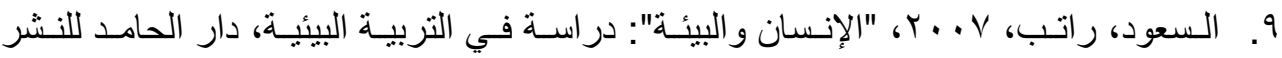

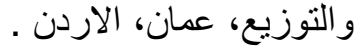

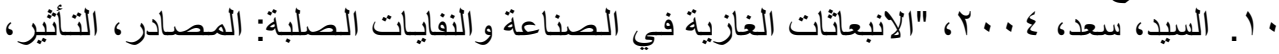

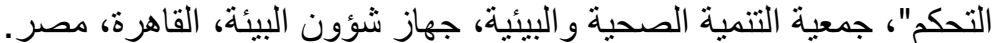

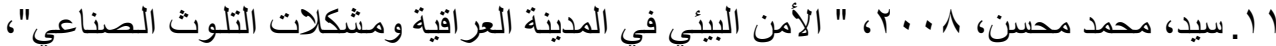

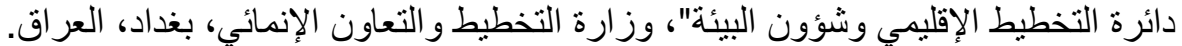

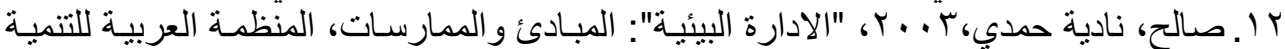

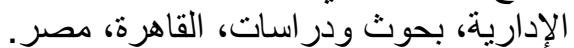

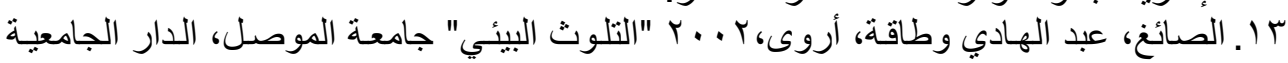

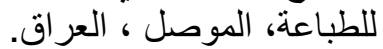

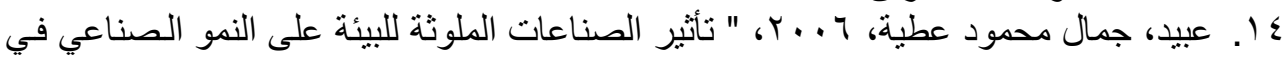

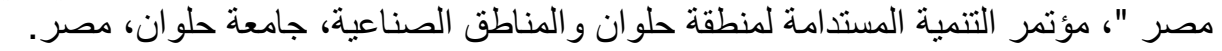

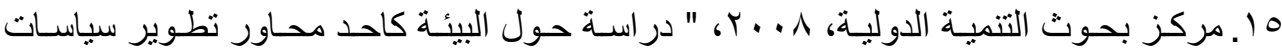
المنشات الصغيرة و المتوسطة في مصر "، بالتعاون مع الوكالة الكندية للتنميـة الدولية (IDRA)

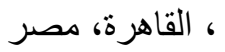
جا ( قاسم، منسى، 999 19، " التلوث البيئي و التتميـة الاقتصادية "، الدار المصرية العامـة للكتاب،

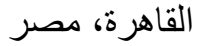

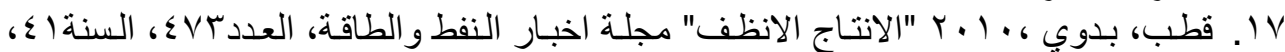

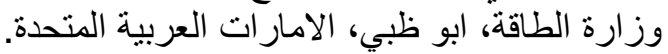

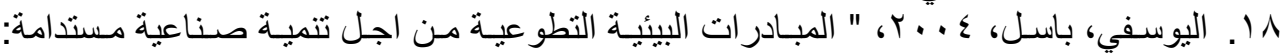

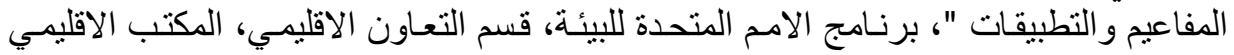

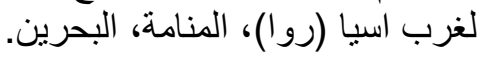

ثانياً- المراجع باللغة الاجنبية

1-Berkel, Renevan .1999, "Cleaner production opportunities for small to medium sized enterprises" ,www. p2pays.org/ref/13/2030.pdf

2-Canzhu Gao, 2001," Study and implementation of cleaner production in environmental impact assessment", proceeding of international conference on cleaner production. Beijng, China, paper No. 25.

3- Maged M. Hamed and Yehia Elmahgary,2004, "Out line of National strategy for cleaner production : The case of Egypt ", Journal of cleaner production, Vol. 12.

4-Nicholas Varchaver , 2007," Chemical Reaction ", Fortune , Apr.2.

5- Solid Waste management :Issues and challenges in Asia, 2007, Environmental management centre, Mumbai, India. 


\section{النعمة وحمودي[^r]}

6-The environment Encyclopaedia and directory, 1994, Europa publication limited, England, London.

7-Thomas E. Higgins, 1995," Pollution prevention" : Hand Book, Lewis pub. U.S.A.

8-UNEP,1994,"Government strategies and policies for cleaner production", UNEP industry and environment, Paris , USEPA

9-http://es-apa.gov/ncer/puplications/meeting.

10- www. Nu.ac.za/dancedcleanerproduction . 